Roberto Carlos Pejendino Jojoa

\title{
Optimization of Contact Grids for Solar Cells with Genetic Algorithms
}

Dissertação de Mestrado

Disertation presented to the Programa de Pós-graduação em Engenharia Elétrica of PUC-Rio in partial fulfillment of the requirements for the degree of Mestre em Engenharia Elétrica.

Advisor : Prof. ${ }^{a}$ Patrícia Lustoza de Souza Co-advisor: $\quad$ Prof. Daniel Neves Micha 


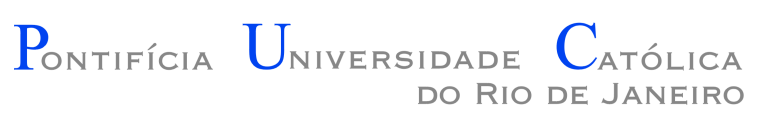

Roberto Carlos Pejendino Jojoa

\section{Optimization of Contact Grids for Solar Cells with Genetic Algorithms}

Disertation presented to the Programa de Pós-graduação em Engenharia Elétrica of PUC-Rio in partial fulfillment of the requirements for the degree of Mestre em Engenharia Elétrica. Approved by the undersigned Examination Committee.

Prof. ${ }^{a}$ Patrícia Lustoza de Souza

Advisor

Centro de Estudos em Telecomunicações - PUC-Rio

Prof. Daniel Neves Micha

Co-advisor

CEFET/RJ

Prof. Omar Paranaiba Vilela Neto

UFMG

Prof. Roberto Jakomin

UFRJ

Prof. Germano Maioli Penello

UFRJ

Prof. Márcio da Silveira Carvalho

Vice Dean of Graduate Studies

Centro Técnico Científico PUC-Rio

Rio de Janeiro, March 8th, 2018 
All rights reserved.

\section{Roberto Carlos Pejendino Jojoa}

Majored in Electronic Engineering by the University of Nariño (Pasto - Colombia) in 2013. He works in the area of nanotechnology researching ways to obtain greater efficiency of solar cells.

Ficha Catalográfica

Pejendino Jojoa, Roberto Carlos

Optimization of contact grids for solar cells with genetic algorithms / Roberto Carlos Pejendino Jojoa; advisor: Patrícia Lustoza de Souza; co-advisor: Daniel Neves Micha. - 2018.

$81 \mathrm{f}$ : il. color. ; $30 \mathrm{~cm}$

Dissertação (mestrado) - Pontifícia Universidade Católica do Rio de Janeiro, Departamento de Engenharia Elétrica, 2018.

Inclui bibliografia

1. Engenharia Elétrica - Teses. 2. Células fotovoltaicas;. 3. Otimização de redes de contato;. 4. Algoritmos genéticos;. 5. Dedos coletores. I. Souza, Patricia Lustoza de. II. Micha, Daniel Neves. III. Pontifícia Universidade Católica do Rio de Janeiro. Departamento de Engenharia Elétrica. IV. Título.

CDD: 621.3 
To my mother, for her unconditional support and encouragement. 


\section{Acknowledgments}

First of all, I want to thank my dear mother Gloria, for her love, for believing in me, her wise advice and unconditional support. To my brother Oscar, grandparents, uncles, family, and friends, to all those people who sent me messages of encouragement and energy.

To my adviser teacher, Patricia, for the teachings, the motivation, the suggestions and all the contributions to the work. Thanks for all the trust and patience.

To the entire Labsem team, José, Janeth, Daniel, Luciana, Rudy, Eleonora, Pedro, Elaine, Guilherme, Renato, Lesslie, Mauricio, Marcelo L., Roberto, Germano, Rogeiro, Eliseu, Víctor, Edgard, Beatriz, Marcelo R., Paulina, for the academic and personal support, for the timeshare, all the advice, and patience that they always had with me. They never denied me a favor when I needed it, thanks to each one of them for their camaraderie and for making my stay here pleasant, I wish all of you good health and the best of success in all your future projects.

To my friends and comrades of battle, of the PUC-Rio, to those who remain and to those who have left, to all the new friendships that I formed during my stay in the academy. Thanks to everyone for the shared moments and the advice givens, from each one I have a great memory.

To all the professors of the PUC-Rio who shared their knowledge and contributed to my academic and professional training. Finally to the CNPq, CAPES and the PUC-Rio for the financial aid granted, without which this work could not have been carried out. 


\section{Abstract}

Pejendino Jojoa, Roberto Carlos; Souza, Patrícia Lustoza de (Advisor); Micha, Daniel Neves (Co-Advisor). Optimization of Contact Grids for Solar Cells with Genetic Algorithms. Rio de Janeiro, 2018. 81p. Dissertação de mestrado - Departamento de Engenharia Elétrica, Pontifícia Universidade Católica do Rio de Janeiro.

High electrical resistances in series and low resistances in parallel are sources of losses in Photovoltaic (PV) devices. In devices that operate under concentration, these are often the main limiting factors for increasing conversion efficiency. Excluding external factors associated with failures in the production process, the series electrical resistance depends on factors intrinsic to the materials and the layer structure of the photovoltaic device. Thus, to minimize their value it is extremely important to properly plan these constructive parameters prior to the production of the devices. One of the most striking factors in the series resistance is the design of the mesh of collecting fingers of the frontal electrical contact. On the other hand, minimizing the series resistance of the electrical contact requires the increase of the metallic area of the frontal surface, which serves as a window for solar radiation. Therefore, there must be a commitment to reduce electrical and optical losses. In this work, we present the results of the optimization of the design of the mesh of collecting fingers for the frontal electrical contact for three different geometries obtained by genetic algorithms. The geometries chosen were the rectangular, traditional for the production of this type of device, hexagonal and diamond. In addition, we compared the results obtained with those of a device produced with an optimized mesh by an analytical calculation method. At the end, we discussed the improvements introduced by the new geometries and presented the optimized configuration. which was obtained for a solar cell of size $5 \times 5$ $\mathrm{mm}$ with a rectangular structure of fingers, with a reduction in losses of $54.42 \%$ that leads to an approximate increase of $1.40 \%$ in efficiency.

\section{Keywords}

Photovoltaic cells; Contact grids optimization; Genetic algorithms; Fingers collectors 


\section{Resumo}

Pejendino Jojoa, Roberto Carlos; Souza, Patrícia Lustoza de; Micha, Daniel Neves. Otimização de redes de contato para células solares com algoritmos genéticos. Rio de Janeiro, 2018. 81p. Dissertação de Mestrado - Departamento de Engenharia Elétrica, Pontifícia Universidade Católica do Rio de Janeiro.

Altas resistências elétricas em série e baixas resistências em paralelo são fontes de perdas em dispositivos Fotovoltaicos (PV). Em dispositivos que operam sob concentração, esses costumam ser os principais fatores limitantes para o aumento da eficiência de conversão. Excluindo fatores externos associados a falhas no processo de produção, a resistência elétrica em série depende de fatores intrínsecos aos materiais e à estrutura de camadas do dispositivo fotovoltaico. Dessa forma, para minimizar o seu valor é extremamente importante planejar adequadamente esses parâmetros construtivos antes da produção dos dispositivos. Um dos fatores mais impactantes na resistência em série é o desenho da malha de dedos coletores do contato elétrico frontal. Por outro lado, minimizar a resistência em série do contato elétrico requer o aumento da área metálica da superfície frontal, que serve de janela para a radiação solar. Portanto, deve haver um compromisso na redução das perdas elétricas e ópticas. Nesse trabalho, apresentamos os resultados da otimização do desenho da malha de dedos coletores para o contato elétrico frontal para três diferentes geometrias obtidas por algoritmos genéticos. As geometrias escolhidas foram a retangular, tradicional para a produção desse tipo de dispositivo, a hexagonal e a diamante. Além disso, comparamos os resultados obtidos com os de um dispositivo produzido com uma malha otimizada por um método de cálculo analítico. Ao final, discutimos as melhorias introduzidas pelas novas geometrias e apresentamos a configuração otimizada, que foi obtido para uma célula solar de tamanho $5 \times 5 \mathrm{~mm}$ com uma estrutura retangular de fingers, com uma redução de perdas de 54,42\% que leva a um aumento aproximado de 1,40\% em eficiência.

\section{Palavras-chave}

Células fotovoltaicas; Otimização de redes de contato; Algoritmos genéticos; Dedos coletores 


\section{Table of contents}

$\begin{array}{lll}1 & \text { Introduction } & 15\end{array}$

1.1 Research Questions 21

1.2 Objective 22

$\begin{array}{ll}1.3 \text { Organization of the dissertation } & 22\end{array}$

2 Basic principles of solar cells $\quad 24$

2.1 Solar irradiance 24

$\begin{array}{ll}2.2 & \text { Basic scheme of solar cell } \\ 2.3 & 25\end{array}$

2.3 Behavior $p-n$ junction 26

$\begin{array}{lll}2.4 & \text { Photovoltaic effect } & 28\end{array}$

2.5 Efficiency equation 28

2.6 Solar cell electric model 30

2.7 Structure of collector fingers 31

2.8 Modeling of frontal electrical contact of solar cells with rectangular geometry fingers 32

2.9 Equations for losses due to shadowing and resistance 34

$3 \quad$ Genetic algorithms (GAs) $\quad 36$

$\begin{array}{lll}3.1 & \text { Encoding } & 37\end{array}$

$\begin{array}{ll}3.2 & \text { Objective function } \\ 3.3 & 38\end{array}$

$\begin{array}{lll}3.3 & \text { Evaluation } & 39\end{array}$

$\begin{array}{lll}3.4 & \text { Selection } & 40\end{array}$

3.5 Crossover 42

3.6 Mutation 43

3.7 Parameters of Evolution 44

4 Methodology $\quad 46$

4.1 Characteristics of the manufactured reference solar cell 46

4.2 Characteristics of simulator 48

4.3 Genetic algorithms applied to the rectangular geometry 50

5 Results $\quad 54$

5.1 Results obtained by optimization 54

5.2 Applications of optimization by genetic algorithm to other geometries 56

5.3 Test results with variation in the size of the solar cell 63

6 Conclusions $\quad 72$

$\begin{array}{ll}\text { Bibliography } & \mathbf{7 4}\end{array}$ 


\section{List of figures}

Figure 1.1 Global PV solar capacity, by country and region, 20062016. Source: (8).

Figure 1.2 A graphical representation of current solar cell efficiencies by NREL. Source:(22).

Figure 2.1 Standard solar spectra for space and terrestrial use. Source: (41).

Figure 2.2 Schematic view of a solar cell

Figure 2.3 (a) Separate semiconductors. (b) Load, electric field, potential and energy levels in the space charge region of the $p-n$ junction. Source: (44)

Figure 2.4 (a) Equivalent circuit of an ideal solar cell and (b) The $I V$ curve characteristic of a diode under illumination.

Figure 2.5 (a) Equivalent circuit of a real solar cell and (b) $I V$ curve of an ideal solar cell without parasitic resistances (blue) and real model with $R_{S}=1 \Omega$ and $R_{S H}=100 \Omega$ (red). Source:(46).

Figure 2.6 Illustrative diagram of the electrical configuration of a solar cell with the metallic front mesh of collector fingers and the back surface completely covered with metallic layer.

Figure 2.7 (a) Layer structure of a solar cell. In (b) and (c), it is possible to visualize geometric details of the front surface and of a collecting finger, respectively. In (d), the scheme of the electrical resistances, represented by the layers and interfaces of the device.

Figure 3.1 Flow chart of a genetic algorithm (left side) and explanations of the different operations by the application of the genetic algorithm.

Figure 3.2 Roulette wheel shows 8 individual with fitness. $\quad 40$

Figure 3.3 Representation of one point crossover. 42

Figure 3.4 Representation of n points crossover. 43

Figure 3.5 Representation of uniform crossover. 43

Figure 3.6 Representation of the mutation process. 44

Figure 4.1 The $I V$ curve characteristic of the solar cell fabricated. $\quad 47$

Figure 4.2 Simplified scheme of the optimization system. 51

Figure 4.3 Genetic algorithm chromosome. 51

Figure 5.1 Genetic algorithm efficiency graph for rectangular contact mesh.

Figure 5.2 Scheme of the geometries to be optimized. (a) rectangular structure, (b) hexagonal structure, (c) diamond structure.

Figure 5.3 Examples of possible geometries for the collecting fingers:

(a) hexagonal structure and (b) diamond structure. $\quad 58$

$\begin{array}{lll}\text { Figure 5.4 Diagram of a regular hexagon. } & 58\end{array}$ 
Figure 5.5 Genetic algorithm efficiency graph for hexagonal contact mesh.

Figure 5.6 Genetic algorithm efficiency graph for diamond contact mesh.

Figure 5.7 Diagram of the front contacts for each of the optimized geometries, for $h=2 \mu \mathrm{m}$ : (a) rectangular structure (b) hexagonal structure (c) diamond structure.

Figure 5.8 Top view and the configuration of the fabricated solar cells: (a) size $2 \times 2 \mathrm{~mm}$ with 2 fingers, (b) size $3 \times 3 \mathrm{~mm}$ with 4 fingers (c) size $5 \times 5 \mathrm{~mm}$ with 10 fingers.

Figure 5.9 Curves $I V$ characteristics of the solar cells manufactured. The green curve represents a solar cell of size $5 \times 5 \mathrm{~mm}$, the blue curve represents a solar cell of size $3 \times 3 \mathrm{~mm}$ and the red curve represents a solar cell of size $3 \times 3 \mathrm{~mm}$.

Figure 5.10 Losses of fabricated solar cell and each of the structures tested for a solar cell of size $2 \times 2 \mathrm{~mm}$.

Figure 5.11 Losses of fabricated solar cell and each of the structures tested for a solar cell of size $3 \times 3 \mathrm{~mm}$.

Figure 5.12 Losses of fabricated solar cell and each of the structures tested for a solar cell of size $5 \times 5 \mathrm{~mm}$. 


\section{List of tables}

Table 4.1 Parameters of the upper electrical contacts of the manufactured solar cell.

Table 4.2 Fabricated solar cell experimental data.

Table 4.3 Comparison between the experimental and simulated values, considering the height, width and number of fingers of the front contacts of the solar cell manufactured.

Table 4.4 Relationship between the covered and illuminated areas for fabricated solar cell and its simulation, considering the width and the standard number of fingers.

Table 4.5 Limit values for the parameters of the construction of the collecting fingers in the rectangular geometry.

Table 5.1 Comparison of grid data for the fabricated cell and for a cell using the optimal grid dimensions obtained by the GA.

Table 5.2 Comparison of grid data for the fabricated cell and for a cell using the optimal grid dimensions obtained by the GA.

Table 5.3 Results obtained by GA for the construction parameters of the collecting fingers with variation of the maximum height limit.

Table 5.4 Limit values for the parameters of the construction of the collector fingers in the hexagonal and diamond geometries.

Table 5.5 Results obtained by GA for the construction parameters of the collecting fingers with hexagonal geometry with variation of the maximum limit of its height.

Table 5.6 Results obtained by GA for the construction parameters of the collecting fingers with diamond geometry with variation of the maximum height limit.

Table 5.7 Electrical resistance of each layer and total in the manufactured solar cell and those obtained by GA for the geometries tested.

Table 5.8 Best results obtained by GA for the geometries tested.

Table 5.9 Results obtained by GA for rectangular structure with variation of the maximum height limit for a solar cell of size $2 \mathrm{x} 2 \mathrm{~mm}$.

Table 5.10 Results obtained by GA for rectangular structure with variation of the maximum height limit for a solar cell of size $5 \times 5 \mathrm{~mm}$.

Table 5.11 Results obtained by GA for the hexagonal structure with variation of the maximum height limit for a solar cell of size $2 \times 2$ $\mathrm{mm}$.

Table 5.12 Results obtained by GA for the hexagonal structure with variation of the maximum height limit for a solar cell of size $5 \times 5$ mm. 
Table 5.13 Results obtained by GA for the diamond structure with variation of the maximum height limit for a solar cell of size $2 \times 2$ $\mathrm{mm}$.

Table 5.14 Results obtained by GA for the diamond structure with variation of the maximum height limit for a solar cell of size $5 \times 5$ $\mathrm{mm}$.

Table 5.15 The best results obtained by GA for the geometries tested, size of the solar cell $2 \times 2 \mathrm{~mm}$.

Table 5.16 The best results obtained by GA for the geometries tested, size of the solar cell $5 \times 5 \mathrm{~mm}$. 


\section{List of Abreviations}

PV - Photovoltaic

NREAP - National Renewable Energy Action Plan

Mtoe - Million tons of oil equivalent

RES - Renewable Energy Sources

EEA - European Economic Area

IEA - International Energy Agency

GBP - Global Gross Domestic Product

CdTe - Cadmium Telluride

CIGS - Copper Indium Gallium Diselenide

AM1.5 - Air Mass 1.5

AM0 - Air Mass coefficient of zero

IV - Current-Voltage

RNEL - National Renewable Energy Laboratory

CAD - Computer Aided Design

GAs - Genetic Algorithms

ANNs - Artificial Neural Networks

GP - Genetic Programming

MOP - Multi-Objective Programming

c-Si - Crystalline Silicon

SQ - Shockley and Queisser

RAM - Random Access Memory 
Nicola Tesla, Science is but a perversion of itself unless it has as its ultimate goal the betterment of humanity. 


\section{Introduction}

Man throughout history has needed the energy to carry out his daily activities. Initially, he relied on his own physical effort and sometimes helped with animals such as oxen, horses, donkeys, etc. Later, fire and vegetable fuels were the protagonists. At that time, the wood was abundant and free. People lived in small tribes but soon began to emerge villas, towns, and cities. The construction of buildings and population growth generated a greater need for energy and forests began to be overexploited. Therefore, little by little it began to be necessary a control of the supply and the demand of the wood but the polluting effects of the burning of this type of fuels were not considered. (1).

Between the eighteenth and nineteenth centuries with the industrial revolution, the consumption of energy from fossil sources soared, which led man to seek cheaper sources of energy, as required to reduce production costs in the industry. Wood burning and coal were the main sources of energy at this time. The use of these alternative sources generates more pollution. In the twentieth century, due to technological advances in the automotive industry, oil became the main source of energy in the world, but in the 21st century it attracted the attention of all environmental entities around the world, due to global warming, since the combustion of fossil fuels are one of the causes of this phenomenon $(2,3)$. From that moment began the interest and concern to find less polluting and economic energy sources that could replace fossil sources.

Much of the world's population still depends on the burning of fossil fuels to obtain most of the energy it uses, the combustion of this type of fuel releases a large number of pollutants into the atmosphere that deteriorates the health of humanity. It also releases greenhouse gases that contribute to climate change (4). The sources of clean energy diminish the negative impacts generated by fossil sources. Renewable energy has been fundamental in society since it contributes to several sustainable development objectives: social and economic development, access to energy, energy security and mitigation of climate change and reduction of impacts on the environment and health (5).

A big challenge for the coming years is to allow the rapid growth of renewable energies so that they can become the backbone of our future energy system (6). It requires a structural change in the current energy system to 
achieve this transition, and a further development of technology to achieve competitive production that can supply the world's population.

The demand for energy around the world grows every year, but in developed countries it has slowed down or even decreased thanks to technological advances and the reduction of the prices of different renewable energy technologies. Thanks to this fact, some countries have set themselves the objective of providing affordable, safe and sustainable energy to their inhabitants (7). In fact, the percentage of renewable energy consumption worldwide is low, since the energy market is still dominated by fossil fuels (8). To avoid this dependence, some countries have made significant investments in the development of clean technologies (9).

In 2015, large investments were made in wind and solar technologies, which accounted for a high percentage of total global investments in renewable energy (10). In 2016, investments in these technologies were reduced compared to 2015, however, renewable energy plants continue to attract much more investment dollars than fossil or nuclear power plants cite 8. The evolution of renewable energy in developed countries is considerable due to these investments, on the other hand, in developing countries due to their low investments, fossil fuels are still a necessary and indispensable source of energy (11). It is important that investment in renewable technologies increases only to keep up with the growth of electricity demand. Greater investment in research and innovation in clean energy by governments and, in particular, the private sector would be of great help.

In 2016, the production capacity of renewable energy in the world was approximately $921 \mathrm{GW}(12)$. In this same year, the main countries with a total installed capacity of renewable electricity were China, the United States, Brazil, Germany and Canada (8). The production of renewable energy in some countries is considerable but still does not meet the world's energy needs.

One of the most important sources of renewable energy is solar energy, some countries are using this great source of energy to mitigate their energy needs, photovoltaic solar systems in developed countries have become a conventional source of renewable electricity (13). In Figure 1.1, we can observe the global production capacities of solar photovoltaic technology by country and region. China dominates both the use and manufacture of photovoltaic solar energy, but all countries have contributed significantly to the global growth of this type of energy.

The expansion of photovoltaic solar energy is due to the competitiveness of markets, the reduction of costs through technological innovation, the continuous demand for electricity and the fact that developed countries seek to 


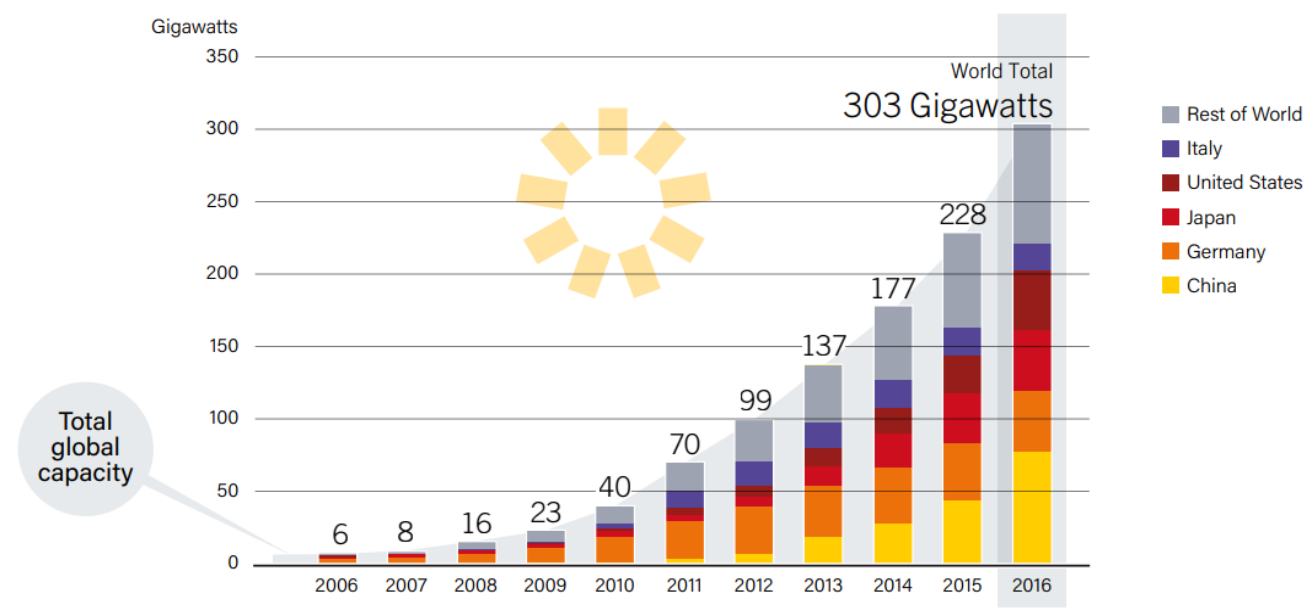

Figure 1.1: Global PV solar capacity, by country and region, 2006-2016. Source: (8).

alleviate pollution and reduce $\mathrm{CO}_{2}$ emissions. At present, for some countries, it is a profitable source of electricity production. The long-term contribution of solar energy to the world's energy needs could be enormous, exceeding our expectations (14).

In Latin America, the photovoltaic solar energy capacity has grown considerably, but it is still low in comparison with the world powers that lead these technologies. Chile is the main installer of the region and occupies the tenth place in the world (8). Brazil has had a great interest in participating in the production of energy through photovoltaic technologies, but most of the projects have stalled due to several limiting factors such as high implementation costs, local regulations and the difficulty of obtaining affordable financing. In much of Latin America, these limitations remain a challenge for the thriving growth of photovoltaic solar energy technologies.

Solar photovoltaic technologies have very low environmental and human health impacts compared to conventional electricity generation technologies. Several indicators show that public acceptance of this type of technology. The increasing participation of PV solar technologies in the global political agenda is of great importance, several governments have set ambitious targets and have begun to implement support schemes aimed at facilitating the implementation of this technology in the market $(15,16)$.

Due to investments and technological advances, the production capacity of photovoltaic solar energy has grown in recent years (17). It is important to continue research in the development of this technology, the expansion of this type of energy can lead to the reduction of production costs of photovoltaic devices that could generate a decrease in the use of fossil fuels. 
We hope that investments in the coming years will be abundant for both the research sector and the production sector. The cost of electricity obtained by photovoltaic systems depends on many factors, the main one being the total energy produced, the operating costs throughout its useful life and the initial financial investments (18). The greater the energy produced, the lower the final value of the electricity. On the contrary, if the modules and other elements of the system are more expensive, electricity becomes more expensive. In this way, the selection of sites with high rates of solar irradiation for installation and the choice of a high-efficiency conversion technology at low cost should be the guides for the implementation of more effective systems.

Photovoltaic solar energy has a large number of applications, the most common is the supply of energy to homes and buildings, it is also used to power emergency communication systems, provide power in remote regions where it is not possible to access the general network of electricity, provide auxiliary energy to boats and cars, etc. As we can see, the uses of solar energy are very broad, although we have a wide variety of applications, the high cost of production and the low efficiency with respect to other types of energy has not allowed the propagation of this technology.

The energy potential of the sun is immense, but even though solar energy is an unlimited resource, achieving the maximum potential of this energy is a challenge, even with this difficulty the use of PV energy has grown exponentially in recent years, having surpassed the 300GWp accumulated around the world until 2016 (19). By 2016, the dominant technology in the market was crystalline silicon, with a share of $93 \%$ of the global annual output. Next came the Cadmium Telluride (CdTe), with $3.1 \%$ of the market, Copper Indium Gallium Diselenide (CIGS) with 1.3\% and amorphous silicon with $0.5 \%$. Technologies with higher efficiencies, such as multiple junction cells with concentrators, had a considerable increase in production by 2012 , reaching 200MWp accumulated, but there was a slowdown in the following years and production in 2016 was only 13MWp. This technology, however, is very promising, since the cost of production of the modules has been falling over time, reaching values close to the flat capture systems (20). However, we still have to consider the operating costs of systems involving the use of concentrators in the final energy price, because they require solar trackers to follow the apparent movement of the sun throughout the day.

The performance of a PV device is measured in terms of its efficiency to convert sunlight into electricity, i.e., the efficiency of a solar cell is defined as the ratio between the electrical power produced from the incident photons to the total incident power. The common approach is to obtain the light generated 
Current-Voltage $(I V)$ characteristics and ascertain the maximum power point. The standard measurement and reporting conditions are defined with respect to the spectral irradiance, total irradiance, temperature and area of the device (21).

Converting sunlight into electricity is a very arduous process. The process is still inefficient as compared to other forms of renewable energy. Increasing the efficiency of photovoltaic cells and modules has been the major goal of researchers in this area in recent years. In academic experiments, the research teams of the Fraunhofer Institute for Solar Energy Systems (Fraunhofer ISE) have been able to create solar cells that can convert 46.0 percent of solar energy into usable electricity (22). Consumer cells as compared to those used in the laboratory for research are considerably less efficient. The silicon solar cells are the most commercial, Kaneka company researchers recently announced that they have developed a silicon solar cell with a record efficiency of $26.3 \%$. The graph of Figure 1.2, shows the best-obtained cell efficiency of different PV technologies published by National Renewable Energy Laboratory (NREL), such efficiencies can still be improved, driving researchers to seek new materials and/or new structures for the devices.

Researchers have tried to find a technique to obtain better efficiency in solar cells. One of the techniques used to improve the efficiency of the solar cells is to place low-resistance electrodes in the rear of the cell, away from the exposed side so that the number of photons which are collected in the front can be increased. Another technique that the researchers used to improve the photon count is to use amorphous silicon and anti-reflective layers on top of the cells, this layer protects the cell components and reduce the sunlight being lost due to reflection (22).

Some research in organic solar cells has focused on optimizing the thickness of their layers (23). Results of simulations in organic solar cells indicate that there is an optimum thickness, according to the mobility of the carrier and the loss of recombination (24). Another research that focuses on the optimization of layer thickness in a dual junction amorphous silicon thinfilm solar cell, the parameters used in the optimization of solar cell power are the concentration of doping and the thickness of the layers (25).

Some researchers have focused on making modifications to the traditional metallic grid pattern in the form of a comb. Some radial patterns of the metallic grid have been proposed to reduce the shadowing losses (26). In other works besides the modification of the geometry of the metallic grid, the effect of the power losses at different lighting levels has been investigated (27). Other research has relied on computational tools, one of them has developed a 


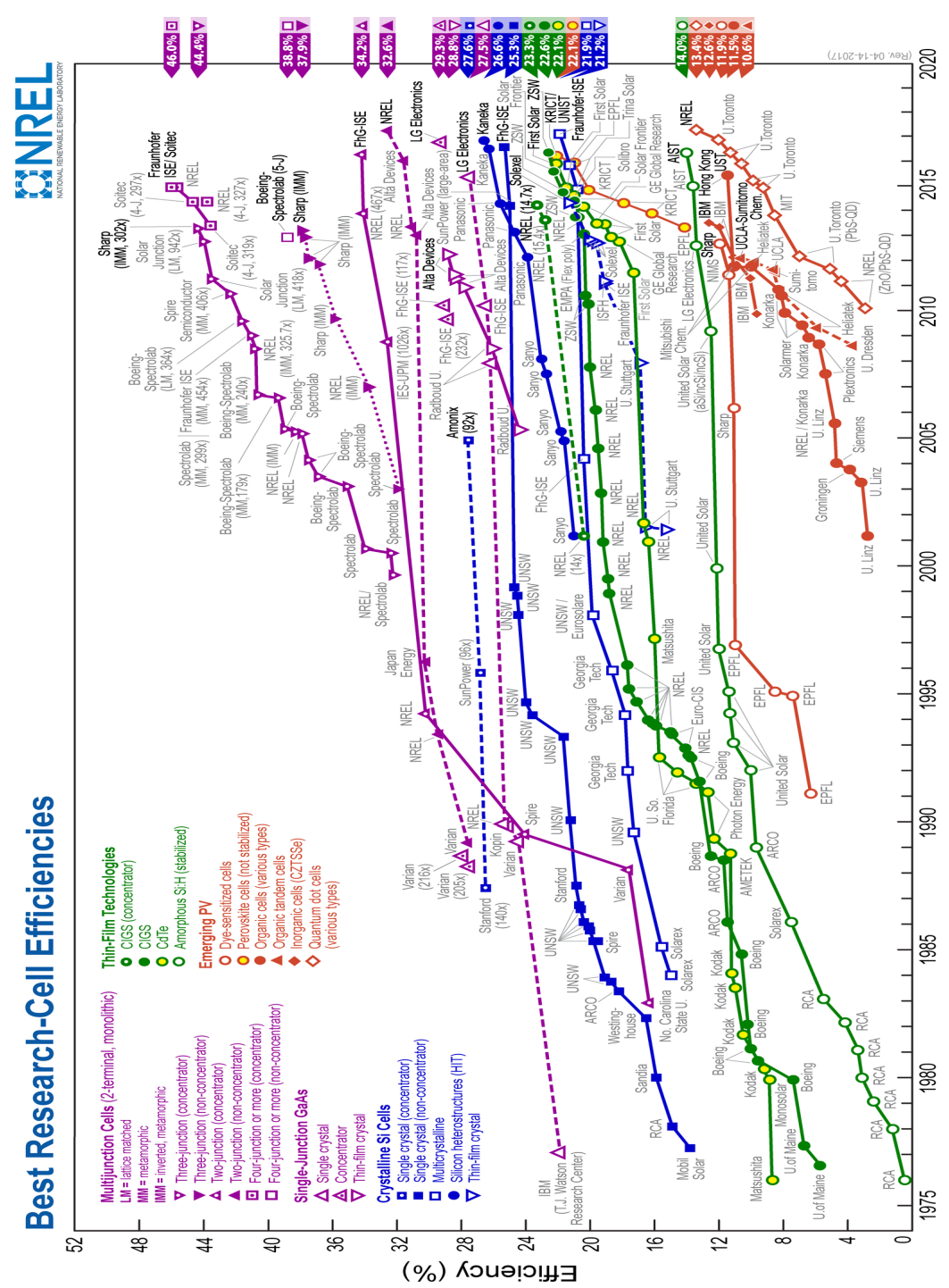

Figure 1.2: A graphical representation of current solar cell efficiencies by NREL. Source:(22).

method of modeling the geometry of the metallic grid looking for the highest output power of solar cells (28). Another investigation is based on topology optimization techniques that are used in mechanical problems and is adapted to electrical problems, this work uses the finite element method to solve the problem of metal grid optimization (29). Computer Aided Design (CAD) software are also a great help in the modeling and simulation of solar cells. In a research project, the 3D TCAD software was used, the objective of this research is to maximize the output power of the cell according to the density of the contact area (30).

Other research proposes optimization techniques based on GAs, the objective of one of the techniques is to extract electrical parameters necessary to model the photovoltaic matrix, it is based on the minimization of the 
quadratic error between experimental and theoretical characteristics (31). Another optimization process based on GAs has as optimization parameters the thickness of each of the layers: window, emitter, base, back surface field, buffer and substrate, and determines the best thickness and doping of each layer. All variables are tested simultaneously and result in an ideal configuration to produce greater efficiency (32). Other investigations resorted to programming tools and optimization methods such as Artificial Neural Networks (ANN), Genetic Programming (GP), Multi-Objective Programming (MOP), among others $(33,34,35,36)$, some of these methods require advanced knowledge of computer programming and specific information about the problem to be solved.

Improvement in the efficiency of a solar cell does not only depend on the materials or structure used to fabricate it, but also on the design of the electrical contacts, such as the front metal grid. There are two main loss mechanisms directly associated with the front grid (37). They are (a) metal grid resistance; (b) shadowing of the cell by the grid.

The thickness and the width of the grid fingers, as well as their spacing, are important parameters to be optimized so as to minimize the losses. If the spacing is too small, the shadowing on the solar cell will be larger, whereas if the spacing is too large, the photogenerated current carriers experience a higher electrical resistance, reducing the produced current. Another loss source is the cross-section of the fingers of the grid. If the fingers are too wide, they increase the shadowing and if they are too narrow or too thin, the series resistance increases, lowering the conversion efficiency. Therefore, there is an optimal value for the width, the thickness and the density of fingers which maximize the solar cell efficiency. Concerning the metal-semiconductor contact, its optimization depends on the material choice and manufacturing process details.

The efficiency of photovoltaic devices has not yet reached its maximum, the existing technology has not been able to fully exploit the sun's energy. There are possibilities to improve photovoltaic devices and in our hands look for ways to achieve it.

\section{1}

\section{Research Questions}

How to achieve an optimal grid pattern in order to get a high-efficiency solar cell? For each set of transport parameters of the semiconductor and metallic materials used in a device, there should be an optimal set of parameters for the design of the collector's fingers which increases the conversion efficiency 
of the device. One way to accomplish this optimization is through Genetic Algorithms (GAs), one of the possible approaches to machine learning.

How can genetic algorithms help in the optimization of the solar cell electric contact? GAs are a powerful tool that can be used for multiple applications. It is based on the search for an optimal solution to a specific problem or to the optimization of a process, a configuration or the result of a function with multiple variables. Around the 1970s (38) the GAs received this name because they were inspired by the natural biological evolution of the $\operatorname{species}(39,40)$. GAs evolve an initial population of individuals through random actions similar to those acting on the mechanisms of evolution, such as mutations, genetic recombination, reproduction, crossover, and selection depending on some criteria. Thus, individuals with greater fitness (maximization or minimization of a target function) are selected and those least adapted to the optimization of the problem are discarded. This is repeated a certain number of times (generations) until it reaches an optimal value or until a stop criterion is met. Finally, an evolved individual is obtained that offers the best possible solution to the problem within the stipulated conditions, i.e., the process of optimization with GA will give us the optimal parameters for the construction of the frontal metallic contacts of a solar cell of specific characteristics.

\section{2 \\ Objective}

The purpose of this work is to use a genetic algorithm to optimize the upper contacts of solar cells, in order to minimize the total losses, namely: series resistance and shadowing losses. Minimizing such losses should lead to an improvement in the solar cells efficiencies. The GA output will be a new optimized upper contact configuration. In addition to the traditional rectangular finger collection scheme, we tested other geometries. The objective is to observe the influence of geometry in the reduction of total losses. In the simulations, we used specific parameters based on real devices manufactured in our laboratory, with which we compared our results. With this work, we intend to develop a tool based on GAs that helps the optimization and design of these devices.

\section{3}

\section{Organization of the dissertation}

This work is divided into the following form:

Chapter 2 presents the basic principles of the functioning of the solar cell. It begins with the explanation of the main concepts and the physical 
phenomena involved in the production of energy through solar cells. It shows the frontal electric contact modeling of solar cells with fingers of rectangular geometry. This chapter also provides the fundamentals and equations to model the project.

In Chapter 3 we present the basic concepts of genetic algorithms, explaining their parts, modes of operation and types of configuration. Chapter 3 continues with the explanation of the methodology used for the application of GA in this work. It also presents the characteristics and specific information of the reference solar cell used in the simulations.

Chapter 4 shows the optimization results obtained for grid metal with rectangular geometry or comb shape. The optimization of the metallic front contacts is also carried out, making a variation in the geometry of the metal grid (hexagonal and diamond), observing the behavior of the total losses in each of the geometries, the results are analyzed and compared with the reference solar cell. In addition, future work is discussed, and some recommendations are proposed that could allow further improvements in the optimization system implemented.

In chapter 5 the thesis is closed and conclusions about the process carried out during the research project are presented. 


\section{Basic principles of solar cells}

\section{1}

\section{Solar irradiance}

For all solar power generation systems, solar irradiance is the input. The measurement of solar irradiance provides knowledge to make important decisions about the efficiency, performance, and maintenance of devices in the future. It is a crucial factor for investments.

The amount of radiant energy received from the sun per unit area per unit time is called solar irradiance and it is a function of wavelength at a point outside the Earth's atmosphere. Solar irradiance is greatest at wavelengths between $300-800 \mathrm{~nm}$. Figure 2.1 shows the solar spectra. Two standard terrestrial solar spectral irradiance distributions are defined for terrestrial use: The Air Mass 1.5 (AM1.5) and The Air Mass coefficient 0 (AM0).

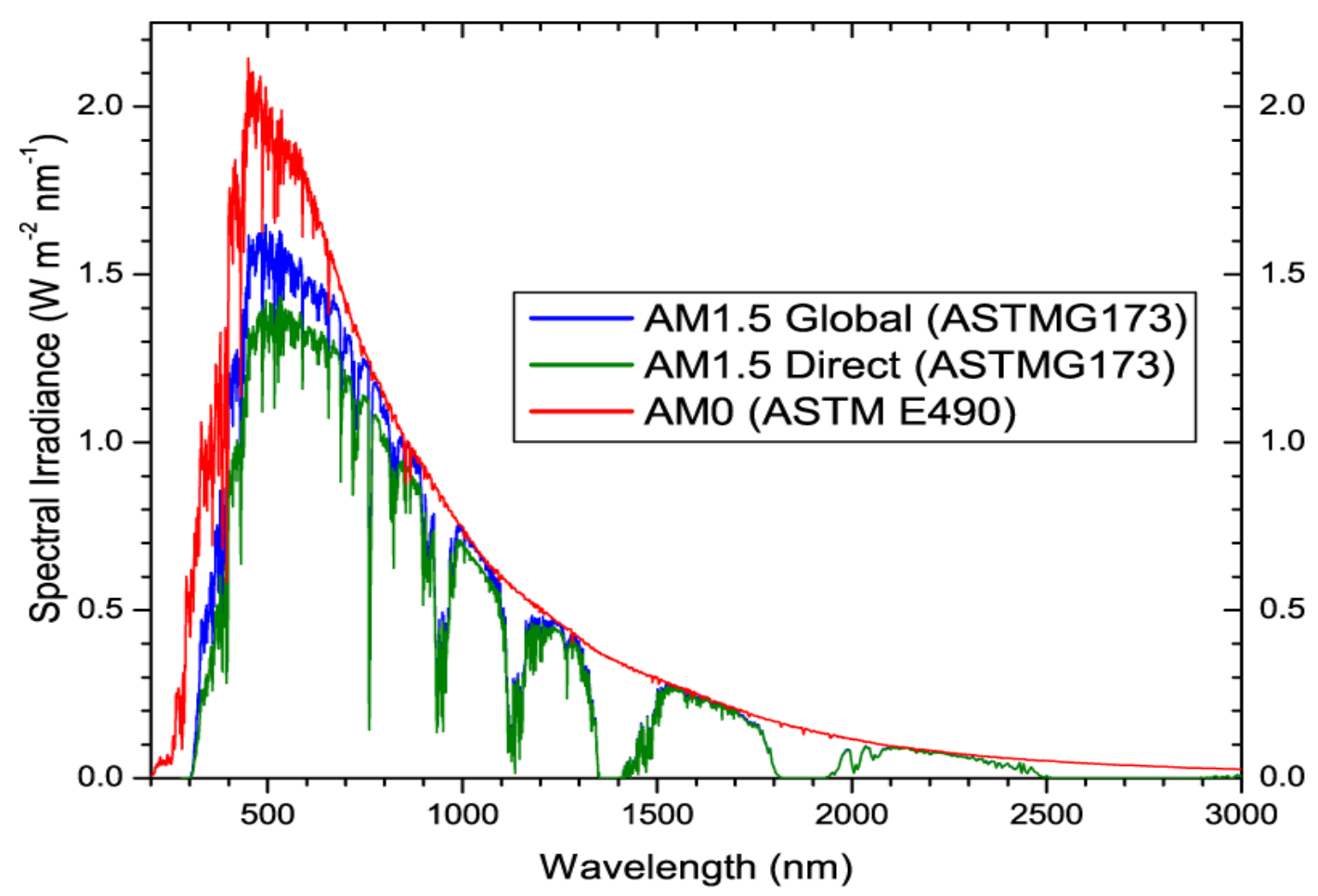

Figure 2.1: Standard solar spectra for space and terrestrial use. Source: (41). 
The AM 1.5 spectrum which corresponds to Latitude $48.2^{\circ}$ is the preferred standard spectrum for solar cell efficiency measurements. The air mass number is dependent on the sun's elevation path through the sky and therefore varies with the time of day and with the passing seasons of the year, and also with the latitude of the observer. The AM1.5 Global spectrum is designed for flat plate modules and has an integrated power of $1000 \mathrm{~W} / \mathrm{m}^{2}\left(100 \mathrm{~mW} / \mathrm{cm}^{2}\right)$. The AM1.5 Direct spectrum is defined for work with solar concentrators. The direct spectrum has an integrated power density of $900 \mathrm{~W} / \mathrm{m}^{2}$ (41). At the outer space, i.e., beyond our terrestrial environment, the solar spectrum has an AM0, which means "zero atmospheres". Solar cells used for space energy applications, such as those on communications satellites, are generally characterized using AM0.

\section{2 \\ Basic scheme of solar cell}

In the most common solar cells, the absorption of photons, which results in the generation of the electron-hole pairs takes place in semiconductor materials. The subsequent separation of the photo-generated charge carriers in direction to the contacts is allowed by the formation of a $p-n$ junction (42). There are different semiconductor materials that are suitable for the conversion of photon energy into electrical energy. Some of these materials are more suitable for photovoltaic applications than others. The semiconductor bandgap determines how much solar energy can be converted into electrical energy. The proper selection of the semiconductor material will depend on the proximity of the photon energy to the bandgap of the material, the photons with less energy than the bandgap are not absorbed. The photon energy must be enough to cover the bandgap of the material, the photons with energy greater than the bandgap lose the excess energy through the emission of phonons.

The outer layers of the solar cells consist of a top and bottom metallic grid that collects the charge carriers and connects the cell to a load, a general scheme of the solar cell can be seen in Figure 2.2. Usually, a thin layer that serves as an antireflective coating covers the topside of the cell in order to decrease the reflection of light from the cell. In order to protect the cell against the effects of outer environment during its operation, a glass sheet or other type of transparent encapsulant is attached to both sides of the cell (43). 


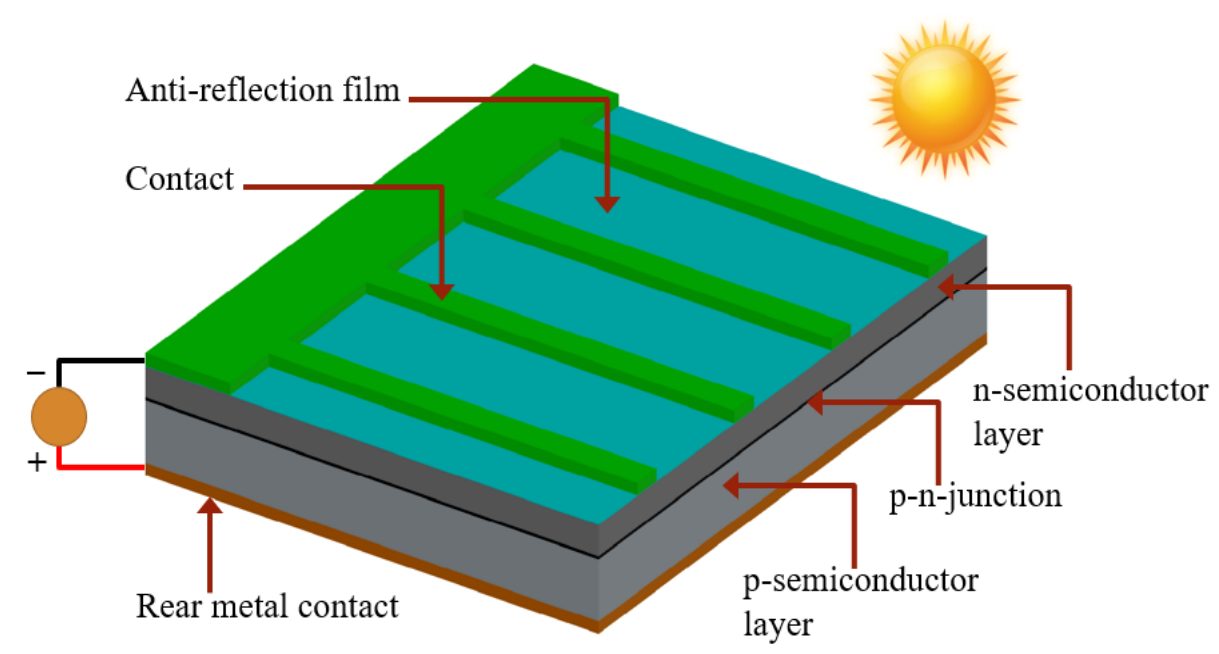

Figure 2.2: Schematic view of a solar cell

\section{3}

\section{Behavior $p-n$ junction}

The basis of the operation of an inorganic solar cell is the $p-n$ junction. A $p-n$ junction is an interface between two types of semiconductor materials, $p$-type and $n$-type. The $p$ side contains an excess of holes, while the $n$ side contains an excess of electrons. To understand what happens in $p-n$ junction, we will assume that the regions of the semiconductor are physically separated before the junction is formed. In this situation the Fermi level $E_{f}$ is next to the conduction band on the $n$-side and next to the valence band on the $p$-side, as shown in Figure 2.3(a).

When the two materials are brought into contact to form the junction, there is a diffusion of the electrons from the $n$-side to the $\mathrm{p}$ side. In the same way, there is diffusion of holes from $p$-side to $n$-side. This diffusion of charges from side to side produces two layers of fixed charges (positive and negative ions), illustrated at the top of Figure 2.3(b)

The region in the vicinity of the junction where there are unbalanced loads is called spatial charge region or transition region. Here an electric field is created, directed from the $n$-side to the $p$-side, which opposes the continuation of the charge motion caused by the diffusion. Field $\varepsilon$ pushes the holes back to the $p$-side and the electrons back to the $n$-side, through a drift current that opposes the diffusion current. The field $\varepsilon$ created in the transition region corresponds to a potential difference $V_{0}$ between the $n$-side and the $p$-side. This difference in potential tends to avoid the passage of majority $p$-side (holes) carriers to the $n$-side and from the majority $n$-side carriers (electrons) to the $p$-side (44). 

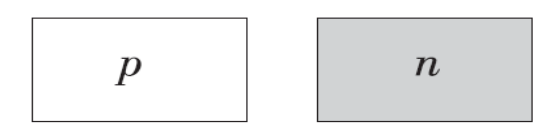

(a)
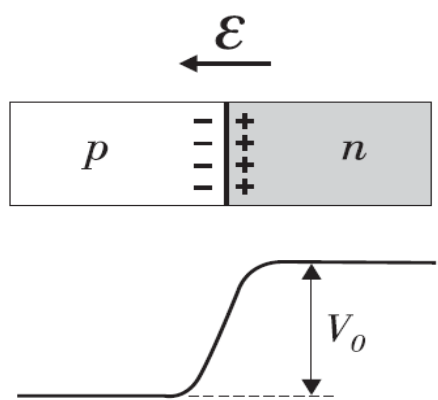

Potential barrier

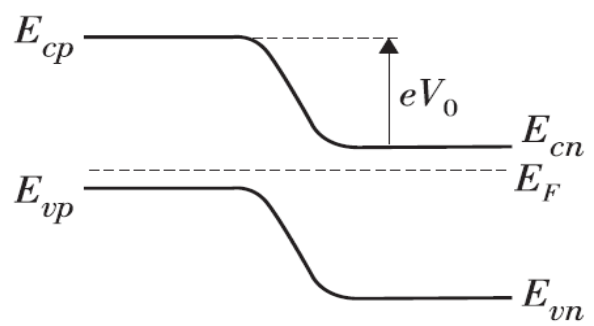

(b)

Figure 2.3: (a) Separate semiconductors. (b) Load, electric field, potential and energy levels in the space charge region of the $p-n$ junction. Source: (44)

Since the energy $E$ of the electron is related to the electrostatic potential $\phi$ by $E=-q \phi$, where $q$ is the absolute charge value of the electron, the difference in the energies of the conduction band between the $p$-side $E_{c p}$ and the $n$-side $E_{c n}$ is,

$$
E_{c p}-E_{c n}=-q\left(\phi_{p}-\phi_{n}\right)=e V_{0}
$$

Consequently, the difference in the energies of the conduction band between the two sides, as well as the valence band, correspond to the potential difference $V_{0}$ created by the field produced in the junction. Due to the formation of the potential variation, shown in the Figure 2.3(b) it is called the potential barrier. The formation of the potential barrier is the most important physical phenomena occurring in the junction, being the main responsible for its electrical characteristics, also has an important implication in the behavior of the energy levels in the junction.

The main semiconductor parameters that determine the design and performance of a solar cell are: concentration of doping atoms, which can be of two different types; donor atoms which donate free electrons, $N_{D}$, or acceptor atoms, which accept electrons and donate free holes, $N_{A}$. The doping levels determine the width of a space-charge region of a junction. Mobility, $\mu$, and diffusion coefficient, $D$, of charge carriers characterize carriers transport due to drift and diffusion, respectively. Lifetime, $\tau$, and diffusion length, $L_{D}$, of the 
excess carriers characterize the recombination-generation processes. Band gap energy, $E_{G}$, absorption coefficient, $\alpha$, and refractive index, $n$, characterize the ability of a semiconductor to absorb radiation.

\section{4}

\section{Photovoltaic effect}

The photovoltaic effect is the basic process in which a solar cell converts sunlight into electricity. When photons are absorbed by a PV cell, the energy from the photon is transferred to an electron bonded covalently to an atom of the solar cell located in the valence band. If that energy is greater than the gap of the material, the energized electron is then able to escape its bond becoming free in the conduction band to conduct electricity. Thus, a solar cell is simply a semiconductor diode that has been carefully designed and constructed to efficiently absorb and convert light energy from the sun into electrical energy. Only a fraction of the incident photons have sufficient energy and the other fraction of energy can not be used, so the efficiency of the solar cells is limited. According to the Shockley and Queisser (SQ) calculations, the efficiency limit that a cell can reach depends mainly on the material gap, the absorption coefficient of the cell and also of some geometric factors (45).

\section{5}

\section{Efficiency equation}

The efficiency is the most commonly used parameter to compare the performance of one solar cell to another. Efficiency is defined as the ratio of energy output from the solar cell to input energy from the sun. Therefore, conditions under which efficiency is measured must be carefully controlled in order to compare the performance of one device to another.

The parameters open circuit voltage, $V_{O C}$, the short-circuit current, $I_{S C}$, the short-circuit current density, $J_{S C}$, current at the point of maximum power, $I_{M P}$, the voltage at the point of maximum power, $V_{M P}$ and the fill factor, $F F$, are determined from the curve $I V$ of an illuminated solar cell. This curve is the result of the behavior of the diode due to the current generated by the absorbed light $I_{L}$, as shown in the simplified equivalent circuit of Figure 2.4(a). The curve $I V$ characteristic of a diode under illumination and the power provided in the maximum point $P_{\max }$ can be seen in Figure 2.4(b). The $I V$ curve indicates that the solar cells are active components since the current flows in the direction opposite to the electric field producing electrical energy. For this reason, the $I V$ curve of the solar cell is inverse to the $I V$ curve generated by passive components (devices that consume energy). 


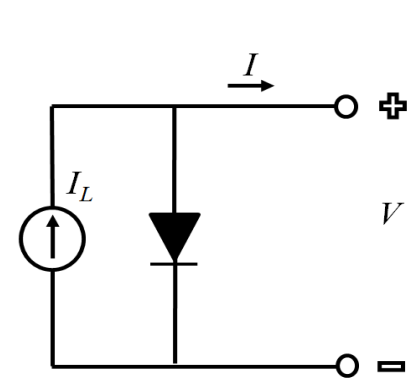

(a)

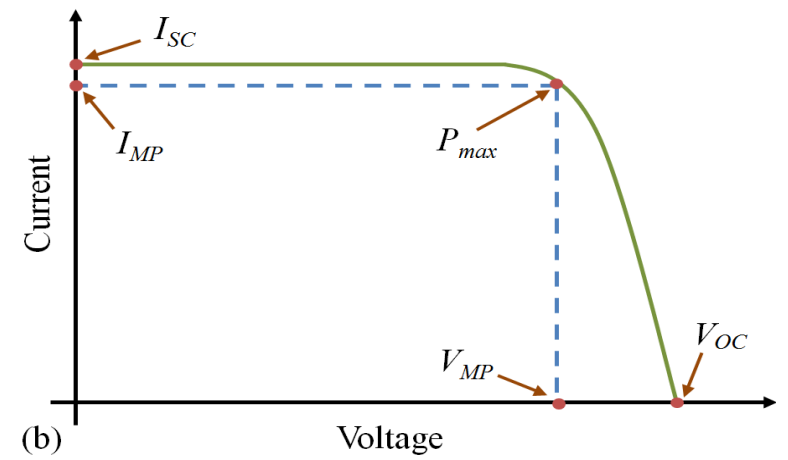

Figure 2.4: (a) Equivalent circuit of an ideal solar cell and (b) The $I V$ curve characteristic of a diode under illumination.

The $F F$ is a measure of the squareness of the $I V$ characteristic and is always less than one. It determines the maximum operating power in relation to the ideal theoretical value $V_{O C} \cdot I_{S C}$ of a PV cell, that is, a fraction between the product at the maximum power point $P_{\max }$ and the product $V_{O C} \cdot I_{S C}$.

$$
\begin{gathered}
P_{\max }=V_{M P} \cdot I_{M P} \\
F F=\frac{V_{M P} \cdot I_{M P}}{V_{O C} \cdot J_{S C}}=\frac{P_{\max }}{V_{O C} \cdot J_{S C}}
\end{gathered}
$$

The efficiency of the solar cell is defined as the fraction of the power of incident sunlight in the cell that is converted into electricity for the circuit. The efficiency $\eta$ of a solar cell is parametrized by its figures of merit, such as the $V_{O C}, J_{S C}$ and $F F$, according to equation 2-5. The factor Pinc is the total incident irradiance and is determined by the properties of the light spectrum incident upon the solar cell.

$$
\begin{gathered}
P_{\max }=V_{O C} \cdot J_{S C} \cdot F F \\
\eta=\frac{V_{O C} \cdot J_{S C} \cdot F F}{\operatorname{Pinc}}
\end{gathered}
$$

$V_{O C}$ is a direct measure of recombination in the device, it is also related to the energy gap(s) of its active material(s). The larger the band gap of the material, the higher the $V_{O C}$. The higher are the recombination rates, the lower the $V_{O C}$ is. In this way, reducing the density of defects, which act as centers of recombination in the devices, increases the efficiency of the device. The $J_{S C}$ is a direct measure of the absorption of solar energy by the materials of the device, as well as the extraction of electric charge carriers generated to the electrical contacts in the form of current. Thus, the increase of the rate of injection of photons by the frontal surface through the deposition of anti-reflective layers, the reduction of the area of the electrical contacts to reduce the shadowing, and the use of materials that absorb more and that create easier ways of 
conduction for the electric charge carriers reaching the contacts improve the photovoltaic conversion in the device. Finally, the $F F$ depends on the $V_{O C}$ and the parasitic and intrinsic electrical resistances that exist in the device. The intrinsic resistances are those associated with the layers and interfaces in the device. As it is very difficult to change the resistance of the active materials, the increase of the $F F$ will basically depend on the optimization of the structure of electric contacts defined in the device. However, the parasitic resistances are associated to errors in the production process of the electrical contacts and the corrosion of layers, which can be minimized.

\section{6}

\section{Solar cell electric model}

Figure 2.5(a) shows an electric model for a real solar cell, containing an $I_{L}$ current generator in parallel with two diodes, representing the sources of radiative recombination current of intensity $I_{D 1}$ and non-radiative recombination current of intensity $I_{D 2}$, and an $R_{S H}$ resistor, representing an alternative parallel path for the passage of electric current $I_{S H}$. In series there is a resistor $R_{S}$, representing the resistances of the materials and their interfaces to the passage of the generated electric current $I$. In this model, $V$ is the electrical voltage delivered to the load (46). Taking into account all these factors, we arrive at equations 2-6 and 2-7, which describe the electric current that is extracted from the device as a function of the electrical voltage at its terminals:

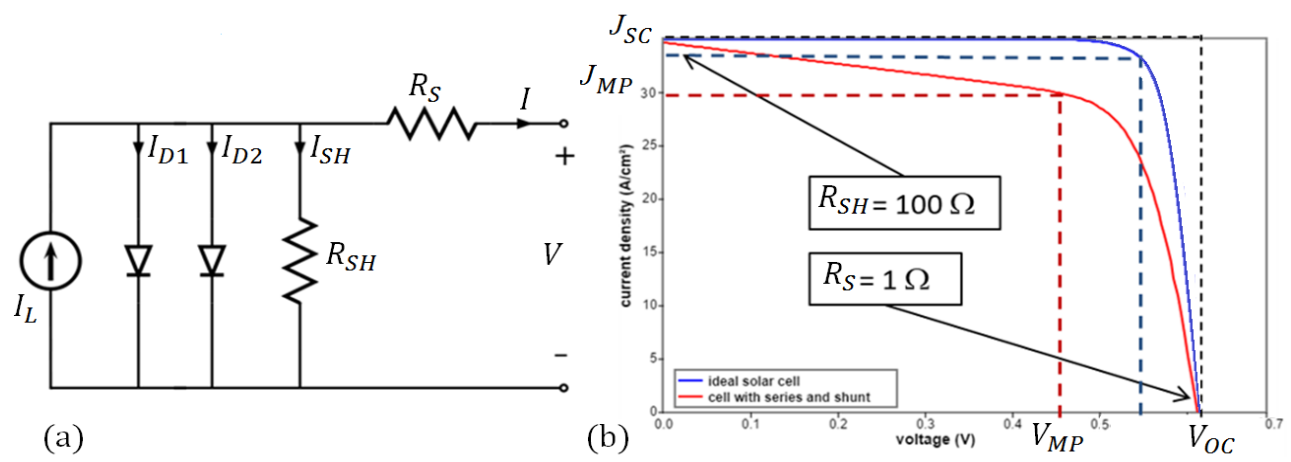

Figure 2.5: (a) Equivalent circuit of a real solar cell and (b) $I V$ curve of an ideal solar cell without parasitic resistances (blue) and real model with $R_{S}=$ $1 \Omega$ and $R_{S H}=100 \Omega$ (red). Source:(46).

$$
\begin{gathered}
I=I_{L}-I_{D 1}-I_{D 2}-I_{S H} \\
I=I_{L}-I_{01}\left[e^{\frac{e\left(V+R_{S} I\right)}{K T}}-1\right]-I_{02}\left[e^{\frac{e\left(V+R_{S} I\right)}{2 K T}}-1\right]-\frac{V+R_{S} I}{R_{S H}}
\end{gathered}
$$


In the equation 2-7, $k$ is the Boltzmann constant, $T$ is the temperature of the device and $I_{01}$ and $I_{02}$ are the reverse saturation currents of the diodes.

Figure 2.5(b) shows two $I V$ curves (blue and red) of devices containing the same values for the following parameters: $T=25^{\circ} \mathrm{C}$, photocurrent density generated, $J_{L}=35 \mathrm{~mA} / \mathrm{cm}^{2}$, reverse saturation current density of the diodes $J_{01}=2 \times 10^{-10} \mathrm{~mA} / \mathrm{cm}^{2}$ and $J_{02}=0 \mathrm{~mA} / \mathrm{cm}^{2} . R_{S}$ and $R_{S H}$ in the blue solid curve presents ideal values, which are, $R_{S}=0 \Omega$ and $R_{S H} \Rightarrow \infty$, and in the red solid line $R_{S}=1 \Omega$ and $R_{S H}=100 \Omega$. In this way, one can see how the electrical resistance associated with the electrical contacts is an important optimization factor for photovoltaic devices.

Any PV system benefits from a high value of $F F$. However, in particular, systems that operate under concentration are more sensitive to this parameter (47). When very high electric currents pass in a PV device, its resistance in series becomes the great limiting factor of efficiency, because the power loss by Joule effect in the electrical contacts is very high. Thus, the systems do not reach very high concentration factors and operate at concentrations of 10 to 500 suns (48), values well below the maximum solar concentration of about 46000 suns.

\section{7}

\section{Structure of collector fingers}

Several designs for the electrical contacts of a PV device have already been proposed. However, the most common design found commercially is with a metal cover across the back surface (where light does not enter) and a drawing with fingers and rectangular busbars on the front surface, as shown in Figure 2.6. Other more advanced designs may be mentioned, but its commercial production is more complex, such as cells with back contacts (49) and conventional cells with rectangular collector fingers and busbars with different geometries such as triangular and diamond $(50,51)$.

The design of a finger structure is an optimization problem. There is a compromise between reducing the electrical resistance in series that the solar cell presents which would thereby increase its $F F$ and increasing the injection of sunlight on this surface which would thereby increase its $V_{O C}$ and $I_{S C}$. Larger and more numerous collector fingers with a small spacing between them reduces the electrical resistance. In contrast, the more metal on the front surface, the less light is injected. Balancing the existing relationship between resistance and shadowing is the challenge in the construction of the collecting fingers. 


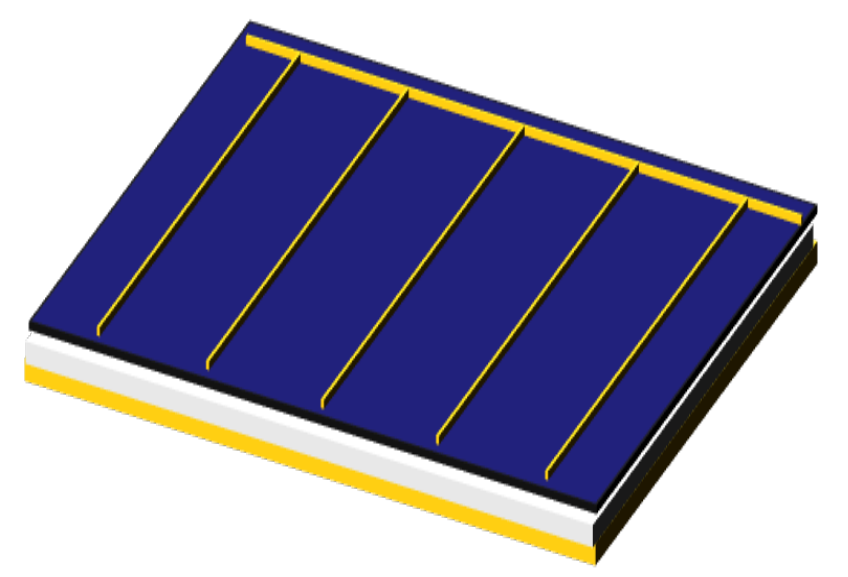

Figure 2.6: Illustrative diagram of the electrical configuration of a solar cell with the metallic front mesh of collector fingers and the back surface completely covered with metallic layer.

\section{8}

\section{Modeling of frontal electrical contact of solar cells with rectangular geometry fingers}

A solar cell is composed of a series of layers, as shown in Figure 2.7(a). In this very common example for cells produced by epitaxy, the following layers are represented: 1) Frontal mesh of electrical contacts (collecting fingers), 2) Contact layer, 3) Emitter, 4) Base , 5) Back Surface Field, 6) Substrate, 7) Back Electrical Contact and 8) Anti-Reflective Layer. Additionally in the Figure 2.7, directions and locations for light incidence (thick red arrows) and the electric current path in direction to the front contact in the device (thin blue arrows) are represented by arrows. When the electric current reaches the collector fingers, it travels laterally to the busbars, as shown in Figures 2.7(b) and 2.7(c). Figures 2.7(b) and 2.7(c) also show geometric details of the front surface of the device and a collecting finger, respectively, where $w$ is the lateral dimension of the device, $n_{f}$ is the number of collecting fingers, $S$ is the distance between two collecting fingers and $l, d$ and $h$ are the length, width, and height of a collecting finger, respectively.

The electrical resistance model of the device shown in Figure 2.7(a) should take into account the individual resistances of each layer $R_{i}$ and the resistance defined by the interfaces formed by the superposition of the different layers $R_{i, j}$. In addition, one must pay attention to the paths taken by the electric current in the different layers. The scheme of Figure 2.7(d) represents the complete model of the electrical resistances presented by this configuration. The electrical current in this device flows from the bottom upwards, i.e., from the back to the front electrical contact, through all its layers, except 


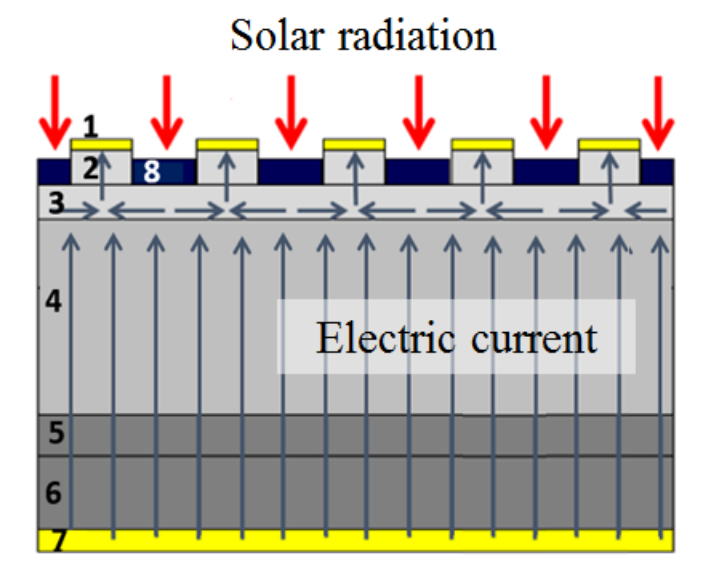

(a)

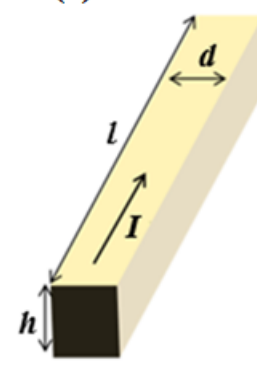

(b)

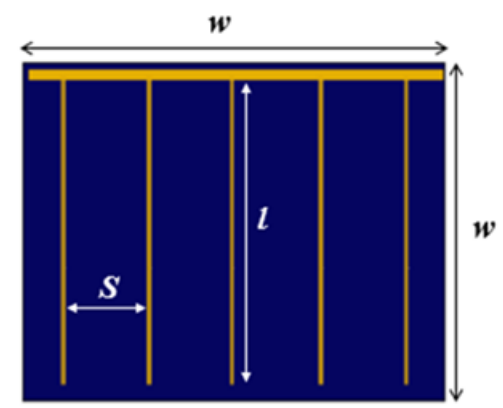

(c)

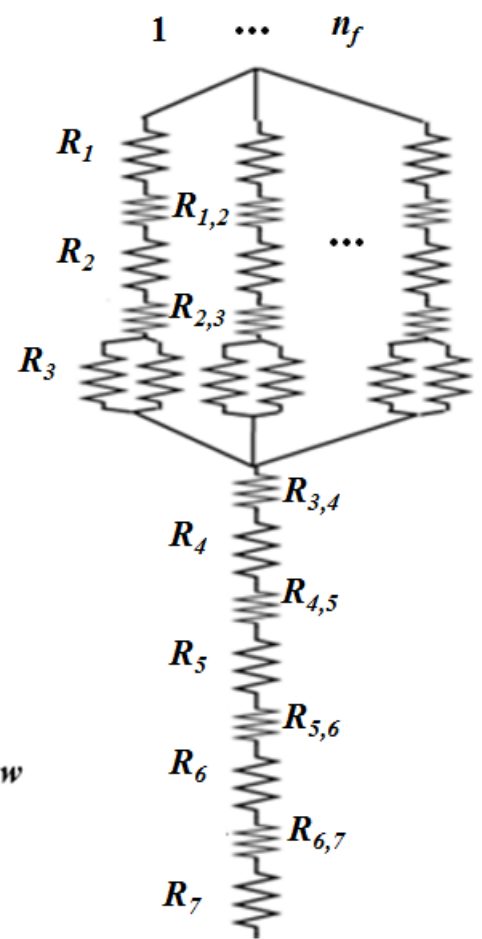

(d)

Figure 2.7: (a) Layer structure of a solar cell. In (b) and (c), it is possible to visualize geometric details of the front surface and of a collecting finger, respectively. In (d), the scheme of the electrical resistances, represented by the layers and interfaces of the device.

for the anti-reflective layer, which is usually bad conductor of electricity. In this example, then, the top layers are $p$-type semiconductors and the $n$-type bottom ones. When the electric current arrives at the emitter, it is led laterally, dividing towards the $n_{f}$ front electrical contacts. For this reason, there is a parallel connection from this point.

The equations that define the electrical resistances represented in Figure 2.7(d) are expressed in relations 2-8 to 2-12. A more detailed explanation can be found in the reference (52).

$$
\begin{gathered}
R_{i}=\frac{\rho_{i} \cdot L_{i}}{A_{i}}, i=1,2,4 \ldots 8 \\
R_{3}=\frac{\rho_{S_{3}} \cdot(S / 2)}{3 w} \\
R_{i, j}=\frac{\rho_{C_{i, j}}}{A_{i, j}} \\
\rho=\frac{1}{e N \mu} \\
\rho_{S}=\frac{\rho}{t}
\end{gathered}
$$


The electrical resistance in each individual semiconductor or metallic layer, except for the emitter, is given by the second law of Ohm (equation 2-8), where $\rho_{i}$ is the specific resistivity of the layer material, $L_{i}$ and $A_{i}$ are the thickness and area of the section where current flows, respectively. The area of layers 4 to 8 is the total area of the device, i.e., $A_{4}=A_{5}=A_{6}=A_{7}=A_{8}=w^{2}$. The area to be used for $R_{2}$ is the area of the collecting finger, that is, $A_{2}=l \cdot d$. At the collector finger, the electric current runs sideways to the bus. In this way, the area to be considered is the lateral area, defined by the height and width of the collecting finger, i.e., $A_{1}=h \cdot d$. In a semiconductor material, the specific resistivity can be calculated knowing the doping level $N$ of the material and the mobility $\mu$ of the electric charge carrier, according to equation $2-11$. For the emitter, it must be taken into account that the electric current increases as you get close to the collecting finger. Thus, we arrive at equation 2-9, where $\rho_{S 3}$ is the sheet resistance of the emitter material. The term $1 / 3$ that appears in equation 2-9 comes from a geometric factor of the rectangular configuration. When considering other geometries, this factor changes. The sheet resistance is related to the specific resistivity of the material through equation 2-12, where $t$ is the thickness of the layer. Equation 2-10 represents the resistance of the electric contact between layers $i$ and $j$, where $\rho_{C i, j}$ is the contact resistivity between layers and $A_{i, j}$ is the contact area.

The total series resistance of the device after considering the circuit of Figure 2.7(d) is defined by equation 2-13.

$$
R_{S}=\sum_{i=4}^{8}\left(R_{i}+R_{i-1, i}\right)+\frac{1}{n_{f}}\left[\sum_{i=1}^{2}\left(R_{i}+R_{i-1, i}\right)+\frac{R_{3}}{2}\right]
$$

\section{9}

\section{Equations for losses due to shadowing and resistance}

Having defined $R_{S}$ according to the parameters of the materials and the layers of the device, it is possible to establish the $X_{R}$ losses generated by the Joule power dissipation in the series resistance of the device through equation 2-14 below:

$$
X_{R}=1-\frac{P_{\text {Mreal }}}{P_{\text {Mideal }}}=1-\frac{I^{M}\left(R_{S} \neq 0, R_{S H} \rightarrow \infty\right) \cdot V^{M}}{I^{M}\left(R_{S}=0, R_{S H} \rightarrow \infty\right) \cdot V^{M}}
$$

In the equation 2-14, $P_{\text {Mreal }}$ is the maximum power obtained through the $I V$ curve for the real device, where the effects of the radiative recombination through the $I_{D 1}$ current and the series resistance in the photovoltaic generation are considered. To consider only the effects generated by these contributions, $I_{02}$ is set to $0 \mathrm{~mA} / \mathrm{cm}^{2}$ and $R_{S H}$ to $\infty$ in equation 2-7. $P_{\text {Mideal }}$ is the maximum 
power for the ideal case, i.e., without the contribution of resistors, for this case, $I_{02}$ is set to $0 \mathrm{~mA} / \mathrm{cm}^{2}, R_{S H}$ to $\infty$ and $R_{S}$ to $0 \Omega$ in equation $2-7$. In addition to the losses due to the series resistance, the electrical losses due to the shadowing caused by the collecting fingers on the frontal surface must be considered. $X_{0}$, which is the shaded fraction of the total area according to equation 2-15.

$$
X_{0}=\frac{A_{\text {shadowing }}}{A_{\text {total }}}=\frac{n_{f} \cdot d \cdot l}{w^{2}}
$$

Finally, it is possible to define the total losses $X$, defined by equation $2-16$, where $\left(1-X_{0}\right)$ is a reduction factor.

$$
X=X_{0}+\left(1-X_{0}\right) X_{R}
$$




\section{3}

\section{Genetic algorithms (GAs)}

In the late 1950s and early 1960s, the British biologist Alex S. Fraser (1923-2002) published a series of works on the evolution of biological systems in a digital computer, serving as an inspiration for genetic algorithms (53). The GAs are adaptive methods that can be used to solve search and optimization problems. They are based on the theory of the evolution of the species. Throughout generations, populations evolve in nature in accordance with the principles of natural selection and the survival of the fittest, postulates of Charles Darwin $(38,54)$.

GAs are generally used to solve problems of the form $(f: \varsigma \rightarrow \Re)$, where $\varsigma$ represents the search space and consists of all possible solutions. Depending on the characteristics of the problem the solutions can be represented with complex structures, real numbers, integers or binary numbers. This last representation is the most common in the GAs. In turn, the function $f$ allows the location of each of the existing solutions search space $\varsigma$, i.e., allows us to identify the quality of the solution for a given problem $(55,56,57)$.

The main objective of GA is to find optimal solutions within the search space. The solutions found must satisfy the characteristics of the problem in question. Depending on the problem, sometimes it is only necessary to find suboptimal solutions (solutions that satisfy the problem). Sub-optimal solutions are acceptable in some complex problems with large search spaces, where the identification of solutions is more difficult (58). Figure 3.1 illustrates the basic operation of a genetic algorithm.

Taking into account the specific characteristics of a problem, we must code each of the possible solutions contained in the search space so that the computer can process the data. After the coding of the solutions, the algorithm must generate a considerable number of individuals for the optimization process, generally this procedure is carried out randomly, the newly generated population goes through a selection and evaluation process where the solutions are categorized. During the evaluation, a real number also called fitness, is associated to each individual. With the fitness value we can know if the individual is adequate to meet the specifications of a problem. After evaluation, individuals with better characteristics go through the stages of crossing and 


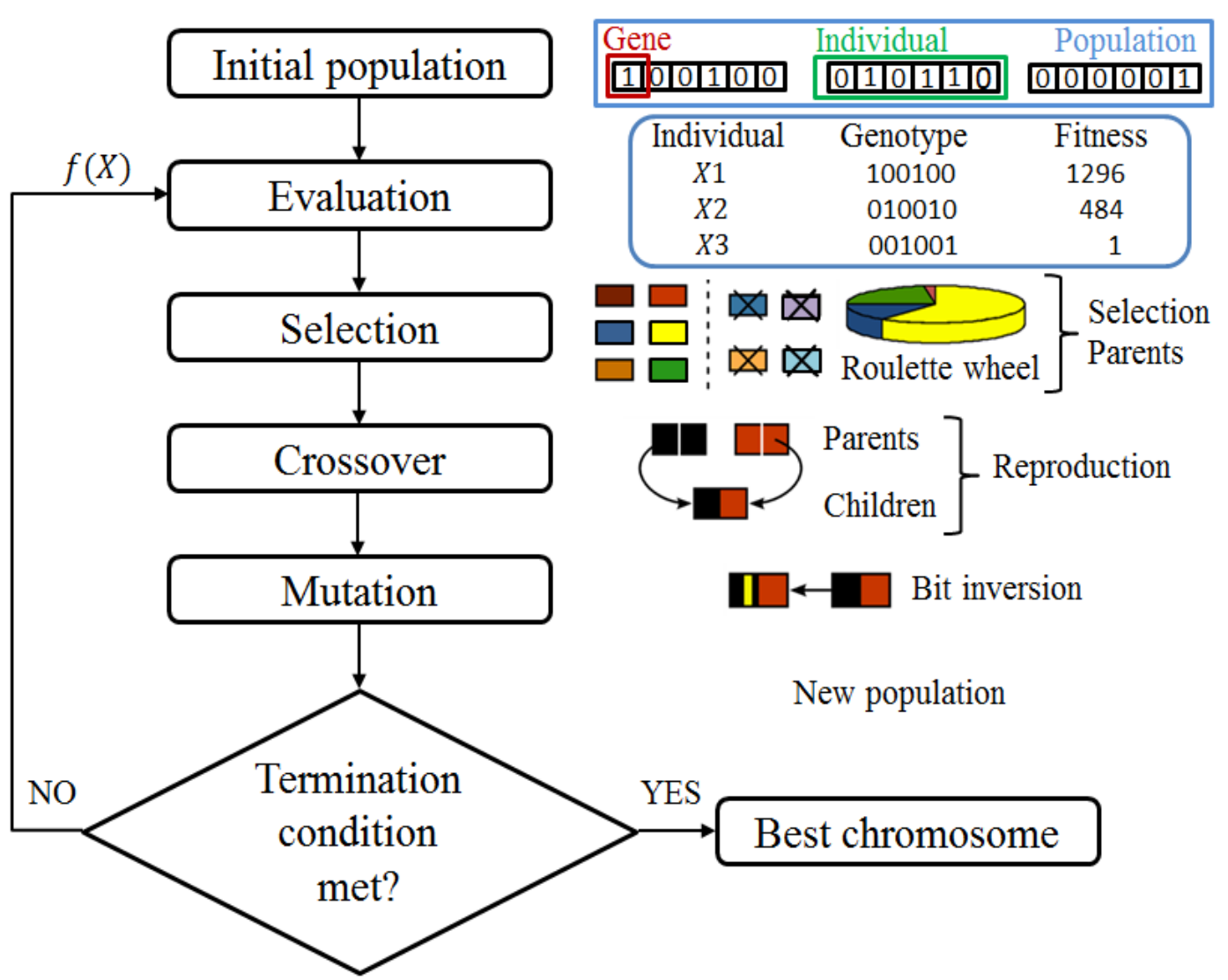

Figure 3.1: Flow chart of a genetic algorithm (left side) and explanations of the different operations by the application of the genetic algorithm.

mutation, a new population is created, thus forming the subsequent generation. This procedure continues until a stop criterion is met (limits and restrictions configured in the GA). The evolutionary process usually ends when the diversity of the population reaches a predetermined minimum, the time period expires or when the maximum number of generations is completed (59) .

\section{1}

\section{Encoding}

It is necessary to codify the solutions of the problem so that the GA can process them and apply the operations that allow it to carry out the evolution. A common approach is to code the solutions as binary strings: sequences of 1 's and 0's, where the digit of each position represents a value of the solution. A possible solution can be represented by a number, a real vector, a string of letters, a list of events or a structure $(55,60)$.

In GA terminology, the solution to a problem can be represented by a set of genes, each gene can be a real number, integer or binary number. A group of genes constitutes a segment and a group of segments composes an individual. 
On the other hand, a group of individuals with the same structure implements a population. A graphic example can be seen in the upper right part of the Figure 3.1.

The first coding works in GAs were usually done using binary values (61). A certain number of bits is assigned to each parameter and a discretization of the variable is performed. This operation simplifies the information grouping the individuals that present the same characteristics in different classes. The number of bits assigned will depend on the degree of precision you want to achieve. Not all parameters are encoded with the same number of bits. However, there are also representations that directly encode each parameter with an integer value, real or floating point. This type of representations allow to work in more specific fields of application of GAs.

The initial population of individuals in most GA configurations is generated randomly (62). In some cases it is necessary to know some kind of previous information about the problem in order to generate an adequate initial population. The generation of the initial population is not a critical phase in GAs, the process of evolution will be satisfactory as long as there is a sufficiently diversified population, so individuals will be able to evolve towards optimal solutions (63).

The representation adopted for a possible solution is called a chromosome (64). The decoding of the chromosome allows the solutions to be evaluated, allowing the construction of the real solution of the problem, phenotype, from the chromosome, genotype. It is important to ensure that chromosomes with different characteristics are decoded in different structures, since it is possible that different chromosomes have equal fitness (59).

\section{2}

\section{Objective function}

The objective function is a mathematical relationship between the decision variables, parameters and a quantity that represents the objective or response of the system (65). It is the measurement of the effectiveness of the model formulated according to the variable parameters. It determines what will be optimized (Maximized or Minimized). The best solution is obtained when the value of the Objective Function is optimal (maximum or minimum value), for a set of feasible values of the variables.

Two aspects that are important in the behavior of the GAs are the determination of an adequate adaptation function or objective function and an adequate coding. During construction, there may be some difficulties with GA behavior, since in the search space there may be a large number of sub-optimal 
solutions, as well as the fact that the global optimum is too isolated from the rest of the possible solutions (66).

The restrictions are limits imposed on the decision variables, many of the optimization problems have an appreciable amount of restrictions, which constitute great challenges to the resolution of optimization problems, since in some cases a great part of the points of the space of search represent invalid individuals. Some problems require that the restrictions have very particular characteristics, in this case it is important to determine which will be the best restriction management strategy, looking for a way to convert an invalid individual into another that does not violate any restriction (67).

A common problem in the execution of the GA is to find an adequate speed of convergence of the algorithm. In some cases, the convergence is very fast and the algorithm converges towards sub-optimal solutions, and in other cases the convergence is very slow, considerably increasing the evolution time. The problem of rapid convergence arises when the selection of the number of individuals is not enough to find optimal solutions. In this case, during the evolution process, individuals with a fitness superior to the rest may emerge, which begin to dominate the population. To avoid domination of the population, the range of variation of the objective function is decreased. The problem of the slow convergence of the algorithm would be solved analogously, but in this case, increasing the range of variation of the objective function (66).

\section{3}

\section{Evaluation}

This stage measures the probability of individuals to survive. The first step is to evaluate each of the individuals of a generation to continue with the selection process. In this process, the score of each gene in the individual is evaluated, assigning a fitness value to each individual selected by the GA. In nature, fitness measures the ability of an individual to adapt to a particular environment.

In the GAs, the fitness indicates the ability of the individual to adjust to the requirements of a problem. Generally, scalar, integer or real values are assigned, the value depends on the degree of fitness of the individual to be selected. The calculation of the fitness of each individual is done through an evaluation function, which is responsible for measuring the degree of quality that individuals have to be part of the population $(68,69)$. 


\section{4}

\section{Selection}

Continuing with the process of evolution, in the selection stage the individuals with more probability of reproduction are selected, according to the survival principle of the species, the fittest individuals are the ones that survive and create a new offspring. Therefore, once evaluated and obtained the score of each of the individuals, the algorithm generates a new population with the individuals of a higher score, i.e., with the best fitness $(70,71)$. There are several methods of selecting individuals, here are some of the most common.

Roulette selection: To associate a score to each individual of a population, the total area of a roulette is divided into fractions, depending on the fitness value of the individual, each fraction contains a certain number of individuals that corresponds to the probability of success for reproduction, an explanatory graph can be seen in Figure 3.2. The roulette is rotated, an indicator in the roulette will select the individual when the roulette stops, obviously, the individual with greater aptitude will have a greater probability of being selected (72).

There may be cases in which the probability of selection of individuals differs greatly, for example, if an individual has a probability of selection of $90 \%$, the probability that the other individuals are selected is minimal, this reduces the genetic diversity of the population, therefore, in this case, the type of selection would not be feasible.Commonly the size of the population remains constant throughout the evolutionary process, in the process of transition from one generation to another, the roulette must be rotated several times until it reaches a sufficient amount of population that allows it to obtain optimal solutions.

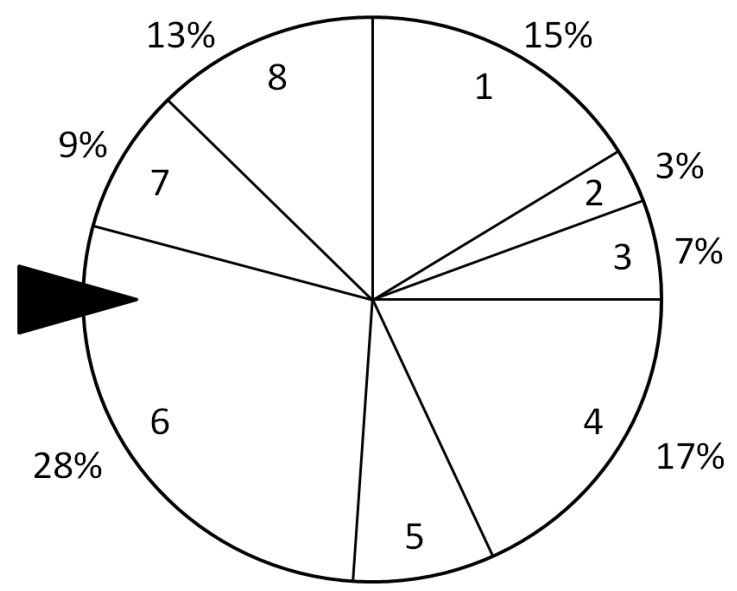

$8 \%$

Figure 3.2: Roulette wheel shows 8 individual with fitness. 
Linear or exponential ordering: In this technique the individuals of the population are ordered according to their respective fitness, each individual is assigned a value corresponding to their position in the ordered population. In this way, the worst individual is assigned the value 1 and the best is assigned the value of the population size. Each probability is assigned to each individual, calculated based on a given distribution, usually linear or exponential. Thus, the selection probabilities are distributed in a balanced manner among the group of individuals with greater fitness, avoiding the stagnation of the evolutionary process and the premature convergence of the algorithm (59).

Elitist selection: The objective of this selection technique is to allow the best individuals from one generation to move on to the next without being altered. This strategy is known as elitist selection and guarantees that the quality of the solution obtained by the GA will not decrease from one generation to the next. Most GAs do not use pure elitism, they use a modified form. During the evolutionary process, it may happen that in a generation the GA does not find an optimal solution, in this case, this technique copies the best individual, or the best individuals of the generation immediately before to be part of the next generation $(73,74)$.

Tournament selection: It consists of randomly choosing subgroups of individuals from the population, the members of each subgroup will compete with each other in a tournament. The objective of the tournament is to compare the fitness value of each of the participating individuals. The winner of the tournament is the individual with the best fitness, who will have the right to participate in the reproduction stage. In order to have a sufficient amount of population that allows the GA to obtain optimal solutions, several tournaments must be carried out. By varying the number of individuals participating in each tournament, the probability of selection can be modified. It would be ideal to have a considerable number of individuals participating in each tournament, this feature increases the probability of selection, leaving little opportunity for reproduction to individuals with low fitness. $(72,75)$.

Hierarchical selection: In this type of selection, the evaluations of the first levels are faster and less discriminatory, the individuals that manage to survive at higher levels are evaluated with more rigor. The advantage of this method is that it reduces the total calculation time by using a faster and less selective evaluation, the objective is to eliminate most individual with low aptitude in the first generations, this type of selection is computationally more expensive in the higher levels where only the fittest individuals remain (75).

The choice of the selection method will determine the GA's search 
strategy. If a selection technique with high pressure is chosen, the search for the solutions will focus on an environment close to the best solutions. If, on the other hand, a less precise selection method is chosen, new search spaces will be generated for its exploration. There are a variety of selection methods. Some seek to improve computational efficiency, others the probability of selecting the best or worst individuals. Some of these methods are, deterministic sampling, sigma scaling, uniform state, stochastic surplus, generational gap, etc (73).

\section{5}

\section{Crossover}

The recombination operator (crossover) is the most important search operator in the GAs. In nature it represents sexual reproduction, this operator exchanges the genetic material of two or more solutions to create new, possibly better solutions. The selected individuals are called parents and are used by the crossover operator to produce an offspring, called a child (76). The objective of the process is that the different parents with high fitness obtained in the selection stage are combined with the new individuals that are generated after this combination. The process of evolution of GA is closely linked to the success of crossover between parents, the desired result of this operation is that it is capable of generating offspring with fitness greater than that of the parents involved in the crossover (69). There are many different crossover algorithms, which can be chosen depending on the characteristics of the problem. $(77,78)$. However, the most used are those that will be detailed below: one point crossover, n points crossover, uniform crossover.

One point crossover: In this operation, a crossing point is randomly selected, the parents are divided at that point, the children are created by exchanging the parts of parents. This technique can be seen graphically in the Figure 3.3.

\section{Parents \begin{tabular}{|l|l|l|l|l|l|l|l|l|l|l|l|l|l|l|}
\hline 0 & 0 & 0 & 0 & 0 & 0 & 0 & 0 & 0 & 0 & 0 & 0 & 0 & 0 & 0 \\
\hline
\end{tabular} \begin{tabular}{|l|l|l|l|l|l|l|l|l|l|l|l|l|l|l|}
\hline 1 & 1 & 1 & 1 & 1 & 1 & 1 & 1 & 1 & 1 & 1 & 1 & 1 & 1 & 1 \\
\hline
\end{tabular} \begin{tabular}{|l|l|l|l|l|l|l|l|l|l|l|l|l|l|l|}
\hline 0 & 0 & 0 & 0 & 1 & 1 & 1 & 1 & 1 & 1 & 1 & 1 & 1 & 1 & 1 \\
\hline
\end{tabular} \\ Children \begin{tabular}{|l|l|l|l|l|l|l|l|l|l|l|l|l|l|l|}
\hline 1 & 1 & 1 & 1 & 0 & 0 & 0 & 0 & 0 & 0 & 0 & 0 & 0 & 0 & 0 \\
\hline
\end{tabular}}

Figure 3.3: Representation of one point crossover.

n points crossover: In this method $\mathrm{n}$ crossover points are chosen randomly, the parents are fragmented in those points, fragments are joined 
alternating the fragmented parts. The graphic procedure can be seen in the Figure 3.4.

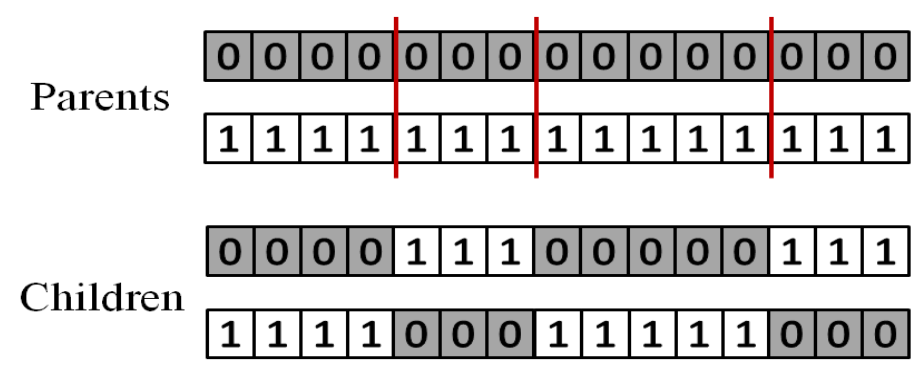

Figure 3.4: Representation of n points crossover.

Uniform crossover: In this technique, to generate the first child each gene of the parent is chosen randomly, the second child is the inverse of the first. The inheritance of a gene is now independent of its position in the chromosome (the positional fragmentation of the $\mathrm{n}$ points crossover is eliminated). This technique can be seen graphically in the Figure 3.5.

\section{Parents}

\begin{tabular}{|l|l|l|l|l|l|l|l|l|l|l|l|l|l|}
\hline 0 & 0 & 0 & 0 & 0 & 0 & 0 & 0 & 0 & 0 & 0 & 0 & 0 & 0 \\
\hline
\end{tabular}

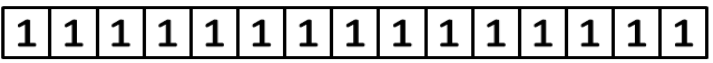

\section{Children}

\begin{tabular}{|l|l|l|l|l|l|l|l|l|l|l|l|l|l|}
\hline 0 & 1 & 0 & 0 & 1 & 0 & 1 & 1 & 0 & 0 & 0 & 1 & 0 & 1
\end{tabular}

\section{\begin{tabular}{|l|l|l|l|l|l|l|l|l|l|l|l|l|l|}
\hline 1 & 0 & 1 & 1 & 0 & 1 & 0 & 0 & 1 & 1 & 1 & 0 & 1 & 0 \\
\hline
\end{tabular}}

Figure 3.5: Representation of uniform crossover.

\section{6 \\ Mutation}

During the process of mutation of an individual the value of the genes, usually only one, varies randomly. After the crossing process one of the descendants, or both, mutates with certain probability. This technique mimics the behavior that occurs in nature, since there is always some kind of error in the passage of the genetic load from parents to children. Generally the probability of mutation used in GAs is low. The mutation operator introduces a degree of randomness in the GA, allowing for population diversity and the evaluation of more points in the search space. $(69,76)$. During the evolution process the mutation operator is gaining importance as the population of individuals converges. (79). As mentioned previously, in the mutation, the random replacement of a gene is more usual, in the case when working with 
binary encodings, it is simply to invert a bit. An example of a binary mutation can be seen in Figure 3.6.

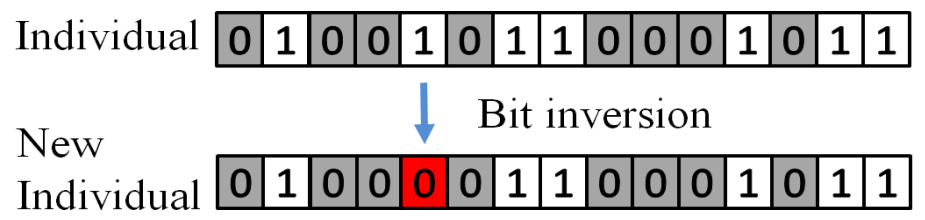

Figure 3.6: Representation of the mutation process.

\section{7 \\ Parameters of Evolution}

In the GA implementation, the selection of the value of the configuration parameters is very important in the evolution process, since it directly affects the solution of the problem. An adjustment of each of the parameters is made during the configuration of the GA, ideally, each parameter must be readjusted according to the characteristics of the population since the GA is dynamic process (80). The parameters that have the greatest influence on GA performance are $(35,59)$ :

Population size: It is generally advisable to have a population large enough to obtain optimal solutions at acceptable intervals of time and to avoid rapid convergence towards sub-optimal solutions. However, very large populations demand a greater computational effort, requiring a longer processing time. Therefore, a balanced relationship must be found between the size of the population and the processing time.

Crossover rate: This parameter represents the probability of success in the crossing of individuals. The selection of a very high crossover rate leads to a large part of the population being recombined in each new generation and decreasing the genetic variety of the population. In turn, this effect can discard individuals with high aptitude and generate a population with individuals with almost equal characteristics that make it difficult to locate the global optimum. On the other hand, a low crossover rate makes the algorithm slow, increasing the convergence time to locate a good solution.

Mutation rate: It is the probability of success of mutation of a gene in the individual. The function of the mutation rate is to maintain the diversity of the population, this effect is very important since it helps to avoid the stagnation of the evolutionary process. Very high mutation rates should not be used, since they would generate extreme population diversity making it difficult to find solutions and affecting convergence towards an optimal solution. 
Steady state rate: Realizes the control of the percentage of the population that will be replaced in each new generation, its purpose is to maintain the optimal solutions found during the evolution process. This parameter is directly affected by the crossover and mutation stages since these genetic operators can discard some solutions. If the percentage of population replaced is high, the convergence of the GA is faster and can lose individuals with high fitness. When the percentage of population replaced is small, the GA becomes slower but avoids the loss of individuals with good fitness

Number of generations: Usually, the number of generations is one of the criteria for stopping GAs. That is, the evolution process ends when the maximum number of generations configured in the GA is reached. A very small number of generations can cause the evolutionary cycle to end prematurely by converging to sub-optimal solutions. In the opposite case, a huge number of generations demands a longer processing time, but allows a better evaluation of the algorithm, helping to avoid convergence to sub-optimal solutions.

Convergence of the objective function: The Convergence is also one of the stop criteria adopted by GAs. When the function does not produce a significant improvement in the solution during a certain number of generations, the processes in the algorithm are automatically stopped. This procedure is carried out in order to avoid that the processing consumes unnecessary high computational times.

Number of rounds: Represent the total number of times a GA will be executed. Since the GA is a probabilistic technique, it is recommended to execute it more than once in order to find better solutions, the new rounds will evaluate other points of the search space where they can find optimal solutions. 


\section{Methodology}

With the information contained in chapters 2 and 3 we can begin to design the optimization system. First, it is important to know the structural characteristics of the reference solar cell, many of these parameters will be used to build a simulator, which will contain the objective function of our GA.

\section{1}

\section{Characteristics of the manufactured reference solar cell}

In order to define the objective function and the initial input parameters of GA, we used the data of a GaAs solar cell produced in our laboratory, whose structure is described in detail in reference (81). Table 4.1 shows the construction parameters of the contact mesh made for this device.

Table 4.1: Parameters of the upper electrical contacts of the manufactured solar cell.

\begin{tabular}{lccc}
\multicolumn{1}{c}{ Parameter } & Symbol & Value & Units \\
\hline Cell width & $w$ & 3 & $(\mathrm{~mm})$ \\
Finger Length & $l$ & 3 & $(\mathrm{~mm})$ \\
Finger width & $d$ & 15 & $(\mu \mathrm{m})$ \\
Finger height & $h$ & 0.215 & $(\mu \mathrm{m})$ \\
Number of fingers & $n_{f}$ & 4 & (units) \\
\hline
\end{tabular}

The data relating to electrical parameters of transport, such as the mobilities of current carriers in the semiconductor layers, were measured in the calibration samples. The values of these parameters, as well as of others, are presented in Table 4.2. They were used as constant parameters in the optimization routine.

The presence of a parallel resistance $R_{S H}$ in equation 2-7, is usually due to manufacturing defects or defects in the structure that act as paths to leakage currrent, rather than a poor design of the solar cell. This parasitic resistance causes the loss of energy in the solar cells, providing an alternative route to the current generated by solar radiation. This deviation reduces the amount of current flowing through the $p-n$ junction and reduces the voltage of the solar cell. 
Table 4.2: Fabricated solar cell experimental data.

\begin{tabular}{lcrr} 
Experimental Data & Symbol & \multicolumn{1}{c}{ Value } & \multicolumn{1}{c}{ Units } \\
\hline Emitter layer mobility & $\mu_{3}$ & 158 & $\left(\mathrm{~cm}^{2} / V / s\right)$ \\
Emitter layer thickness & $L_{3}$ & 100 & $(\mathrm{~nm})$ \\
Emitter layer doping & $D_{3}$ & $2.16 \times 10^{18}$ & $\left(\mathrm{~cm}^{-3}\right)$ \\
Contact layer mobility & $\mu_{2}$ & 110 & $\left(\mathrm{~cm}^{2} / V / s\right)$ \\
Contact layer thickness & $L_{2}$ & 30 & $(\mathrm{~nm})$ \\
Contact layer doping & $D_{2}$ & $4.10 \times 10^{19}$ & $\left(\mathrm{~cm}^{-3}\right)$ \\
\hline
\end{tabular}

An estimated value of $R_{S H}$ can be obtained from the negative inverse of the slope of the $I V$ curve near the short circuit current point. Figure 4.1 shows the experimental $I V$ curve used to obtain the parallel resistance value of the solar cell manufactured, the value obtained is $68 \mathrm{k} \Omega$, this amount will be used in the modeling of the optimization system.

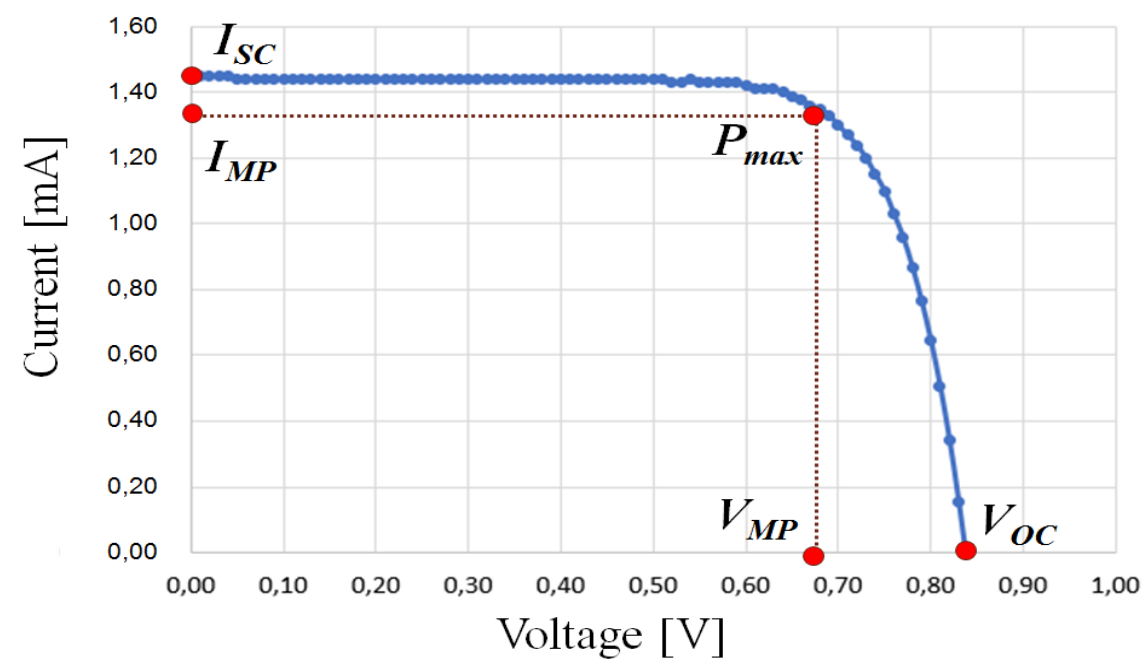

Figure 4.1: The $I V$ curve characteristic of the solar cell fabricated.

The specific resistivity of the material $\rho_{i}$ in equation $2-8$, quantifies the force with which a material opposes to the flow of electric current. A low resistivity indicates a material that easily allows the movement of electric charge. The metal used for construction of the front contacts in the reference solar cell was gold, with a resistivity value of $2.44 \times 10^{-8} \Omega \mathrm{m}$. This value is another of the constants used in the construction of the model.

Another parameter that is taken into account in this work is the intensity of solar radiation. In the characterization of the manufactured solar cell, a simulation of the AM1.5 solar spectrum conditions was performed and the respective measurements were made to obtain the $I V$ curve. 


\section{2 \\ Characteristics of simulator}

In order for the GA to evaluate the quality of a solution, a simulator or a function is necessary. In this work, a simulator will be used for the evaluation of the individuals generated by the GA. In the beginning, we wanted to work with a software specialized in the design and simulation of solar cell contacts, we found some possible candidates, but they were protected by copyright, that is, licensed programs that prevent access to the source code. This protection prevents the direct interaction of the GA with the objective function, which is necessary to execute the optimization process, for this reason, a simulator had to be built to develop the project.

The first computational step to carry out the research was the simulation of a computational model of the reference solar cell (81). This simulator works with the database of the experimentally measured $I V$ curve, together with the basic theory and the equations that are shown in Chapter 2, the code is programmed in the software MatlabßR2016b, this simulator takes into account the physical characteristics and structural elements of the fabricated solar cell. The process of construction of the simulator described in more detail is presented below.

First we define the parameters that will be constant in the computational model of the reference solar cell to be programmed, these parameters are: temperature under standard conditions, $T=298 \mathrm{~K}$, ideality, $I d=1$, solar concentration, $c_{o}=1$, parallel resistance, $R_{S H}=68 \mathrm{k} \Omega$ (calculated from curve $I V$ measured experimentally), Boltzmann constant, $k_{B}=1.3806503 \times 10^{-23} \mathrm{~m}^{2}$ $\mathrm{kg} \mathrm{s}^{-2} \mathrm{~K}^{-1}$, electron charge, $q=1.60217733 \times 10^{-19} \mathrm{C}$. We must also define the input and output parameters of our simulator. For our case, we define $d, h$ and $n_{f}$ as inputs, since they are the most important parameters for the optimization process, and as output, we define $X$ since it is the parameter to be minimized.

After defining the constants and the input and output parameters, a code is created to model each of the resistances that are part of the solar cell. The simulator allows calculating the value of each of the resistances involved in the loss of the photovoltaic device. For the calculation of $R_{1}$ the resistance of the frontal contact metal layer, the simulator uses equation 2-8, some of the data recorded in Table 4.1 and the resistivity of gold, $\rho_{1}=2.23 \times 10-8 \mathrm{~m}$. For the calculation of $R_{2}$ the resistance of the emitter layer, the simulator uses some data related to the electrical transport parameters that are recorded in Table 4.2 and equations 2-9, 2-11, 2-12. With respect to $R_{3}$ the resistance of the contact layer is calculated using Table 4.2 and equation 2-10. In the case 
of $R_{7}$, the resistance of the back contact layer depends on the resistivity of the sheet metal semiconductor and some data recorded in Table 4.1. At the end, the simulator makes the sum of each of the resistances with the equation 2-13 obtaining the total resistance $R_{S}$.

With $R_{S}$ and $R_{S H}$ defined, taking into account the equation 2-7 of electric current generated by the solar cell and the data provided by the experimental $I V$ curve, the simulator calculates the power $P_{\text {Mreal }}$ (taking into account the effect of the resistances) and $P_{\text {Mideal }}$ (without effect of the resistances) that are part of equation 2-14 and that are necessary to calculate the percentage of resistance losses $X_{R}$.

For the calculation of the percentage of shadowing losses, $X_{0}$, the simulator uses equation 2-15 that takes into account the construction parameters of the solar cell manufactured in Table 4.1. At the end having the values of $X_{R}$ and $X_{0}$, the simulator calculates the percentage of total losses $X$ with the equation 2-16.

To perform the validation of the simulator, the input parameters $d, h$ and $n_{f}$ take the values from Table 4.1 used for manufacturing the reference solar cell. The code allows to add output parameters for the validation of the simulator, the parameters selected for the validation are: $I_{S C}, J_{S C}, V_{O C}$, $I_{M P}, V_{M P}, F F$ and efficiency. After making the configuration, the simulator is executed, the results are compared with the experimental data (81), the results of the validation are recorded in Table 4.3 with its corresponding error percentage.

Table 4.3: Comparison between the experimental and simulated values, considering the height, width and number of fingers of the front contacts of the solar cell manufactured.

\begin{tabular}{lccccccc} 
Solar cell & $\begin{array}{c}I_{S C} \\
(\mathbf{m A})\end{array}$ & $\begin{array}{c}J_{S C} \\
\left(\mathbf{m A} / \mathbf{c m}^{2}\right)\end{array}$ & $\begin{array}{c}V_{O C} \\
(\mathbf{V})\end{array}$ & $\begin{array}{c}I_{M P} \\
(\mathbf{m A})\end{array}$ & $\begin{array}{c}V_{M P} \\
(\mathbf{V})\end{array}$ & $F F$ & $\begin{array}{c}\text { Efficiency } \\
(\mathbf{\%})\end{array}$ \\
\hline Fabricated & 1.448 & 14.129 & 0.837 & 1.346 & 0.680 & 0.755 & 8.934 \\
Simulation & 1.381 & 14.153 & 0.830 & 1.286 & 0.657 & 0.737 & 8.659 \\
Error (\%) & 4.592 & 0.170 & 0.836 & 4.443 & 3,367 & 2.384 & 3.074 \\
\hline
\end{tabular}

In Table 4.3 the results take into account the total area of the cell, i.e., all the components of the upper metal layer of the device, in our case are the busbar and the collector's fingers. Comparing each one of the results, a good approximation is observed between the simulated data and the measured values.

In the previous validation, the busbar was taken into account, the size of the busbar is a parameter that in our work will remain constant. The 
optimization process that will be carried out will only focus on the search for the optimal parameters for the design of the collector's fingers, so it will not take into account the busbar in the GA configuration. After removing the busbar from the GA configuration, we performed a test with the simulator in which we only took into account the shadowing area by the collector's fingers of the reference solar cell, the results are recorded in Table 4.4. The comparison with the experimental data of the fabricated solar cell we can see that the elimination of the busbar affects the percentage of losses by shadowing. The objective of the test is to have a reference value of the percentage of losses by shadowing delivered by the simulator and then make a comparison with the optimized results.

Table 4.4: Relationship between the covered and illuminated areas for fabricated solar cell and its simulation, considering the width and the standard number of fingers.

\begin{tabular}{|c|c|c|c|c|}
\hline Solar cell & $\begin{array}{l}\text { Area of the } \\
\text { solar cell } \\
(\mathrm{mm} 2)\end{array}$ & $\begin{array}{l}\text { Area covered } \\
\text { by contacts } \\
(\mathrm{mm} 2)\end{array}$ & $\begin{array}{c}\text { Shadowing } \\
\text { area } \\
(\%)\end{array}$ & $\begin{array}{c}\text { Illuminated } \\
\text { area } \\
(\%)\end{array}$ \\
\hline Fab & 10.245 & 1.084 & 10.581 & 89.419 \\
\hline Simulation & 9.000 & 0.180 & 2.000 & 98.000 \\
\hline
\end{tabular}

After knowing the characteristics of the simulator and validating it, we can say that it is ready to be part of the optimization system.

\section{3}

\section{Genetic algorithms applied to the rectangular geometry}

In Figure 4.2, we can see a simplified scheme of the optimization system and how the simulator plays an important role in the GA evaluation process.

The initial population of individuals is created from the initial data selected in relation to the construction parameters of a standard photovoltaic device, such as width $d$, height $h$, number of collector's fingers $n_{f}$, respecting ranges of values imposed for the system due to the physical limitations of the construction of these devices. The objective function is the total losses, which, in our case, is given by equation 2-16, each individual is evaluated assigning a value that is compared with the conditions and objectives of the optimization. If the values satisfy the limits and restrictions of the problem (these conditions will hardly be met for the first generation of individuals), the simulation ends by providing the optimum values of the parameters for the manufacture of the solar cell. Otherwise, the genetic operators are applied to the individuals, generating random variations of the parameters, these generated variations are 


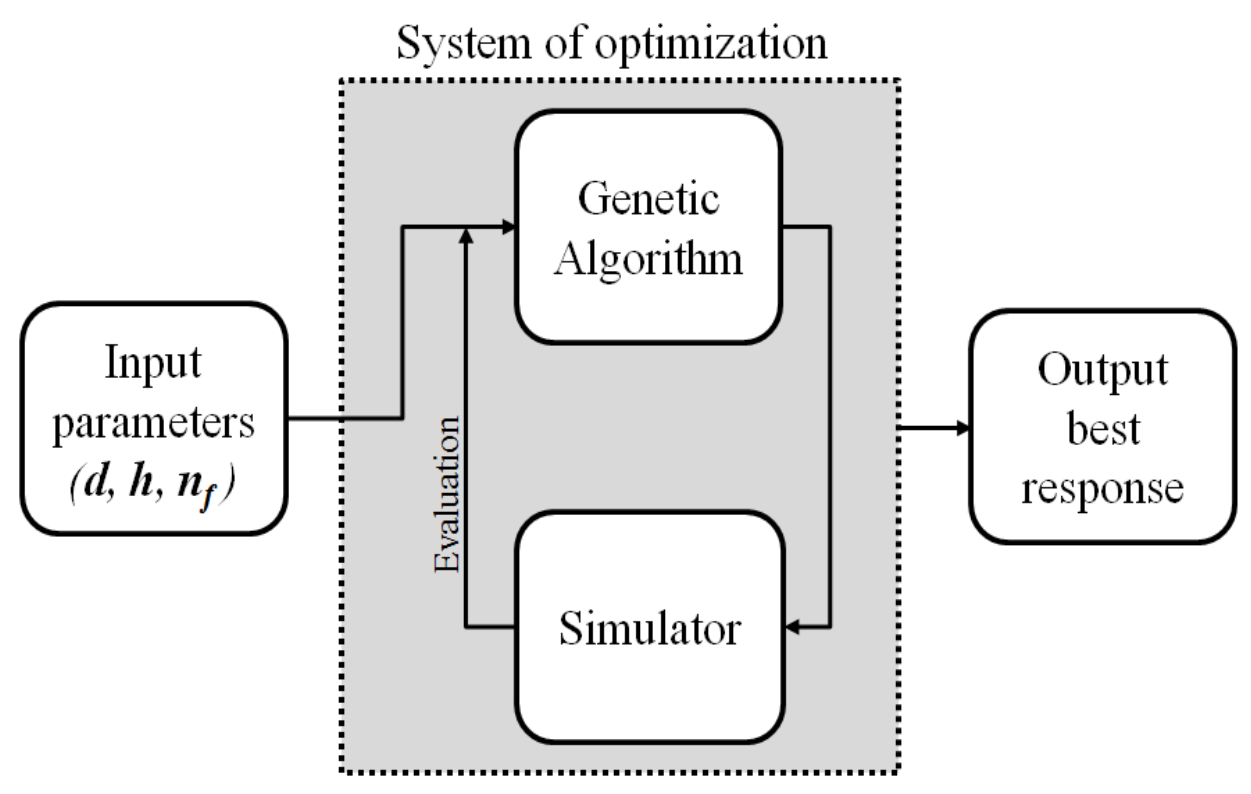

Figure 4.2: Simplified scheme of the optimization system.

combined with the best individuals of the previous generation, thus producing a new generation of individuals. The values for each variable are again limited to the intervals, initially defined. The objective function is calculated for the parameters of each individual of this new generation and its value is compared with the stipulated conditions for optimization. Again, if the conditions are met, the simulation ends, otherwise, the process is restarted until the best results are found.

The size of the population was fixed in 120 individuals, which provides satisfactory exploration capacity of the search space and adequate diversity of the individuals belonging to the population, considering that the proposed optimization problem involves an optimization dependent on three variables, GA genes $\left(d, h, n_{f}\right)$, as shown in Figure 4.3.

\section{Chromosome}

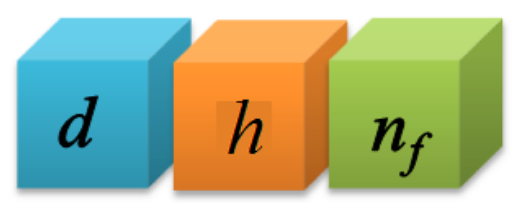

Figure 4.3: Genetic algorithm chromosome.

The maximum number of generations of the genetic algorithm was set to 70 as the stop criterion. In addition, a flexible stop criterion has also been adopted, which interrupts the evolution of the algorithm when the 
average variation of the evaluation function over a predetermined number of generations remains constant.

The technique of selection used to discard individuals of each generation that do not satisfy the optimization conditions was the elitist, which consists in saving the best individual(s) of one generation and reproducing them in the following one, avoiding the loss of important solutions present in individuals with a high fitness and that can be lost during the processes of selection and crossover, thus ensuring that the following evolved generation has a result equal to or better than the previous one, never worse. For the crossing of the individuals, the technique used was the single point crossover and for the mutation, a default function of the GA "mutationadaptible" was used, which takes into account the limits and restrictions and randomly generates the percentage of mutation with respect to the last successful or failed generation. In our case, the mutation rate used was $0.5 \%$. The value of the crossing probability used (crossover rate) was $0.9 \%$.

To avoid the loss of the best individuals throughout the evolutionary process, an elitism criterion was used to substitute individuals. The Elitecount parameter was set to 10 to ensure that the top 10 individuals belonging to the population of a given generation are also present in the next generation.

To apply GA to our system was necessary to define the limits (search space) and constraints to the problem. The ranges of values for each parameter are imposed to avoid solutions that are not physically feasible, such as an amount and width of collector's fingers that define a line greater than the width of the solar cell or that are so small that they can't be fabricated with the current techniques of photolithography available. The limits of values applied to our problem follow in Table 4.5.

Table 4.5: Limit values for the parameters of the construction of the collecting fingers in the rectangular geometry.

\begin{tabular}{crr} 
Parameter & Lower Limit & Upper Limit \\
\hline$d(\mu \mathrm{m})$ & 5 & 1500 \\
$h(\mu \mathrm{m})$ & 0.1 & 2 \\
$n_{f}$ (units) & 2 & 600 \\
\hline
\end{tabular}

The maximum width $d$ of the collector fingers should be half the lateral dimension of the solar cell $w$, and the minimum value is defined by the resolution of the available lithography . As the lower limit for $n_{f}$, we define 2 units and as upper limit 600 units, since that is the maximum value of fingers $w / d_{\text {min }}$ that can be fit inside the solar cell. The length $l$ of the collecting fingers is fixed as being the same value of the lateral dimension of the device, i.e., $w$. 
Finally, the height $h$ of the collecting fingers is limited by economic issues associated with the deposition of very thick layers of noble metals, such as gold, which is used in electrical contacts.

In the GA configuration we have a restriction, this provides a more specific search space for the solution and decreases the evolution process time, the restriction is as follows: the product between the parameters $d$ and $n_{f}$ must be less than the width of the solar cell $w$.

The computer used for optimization process has the following characteristics: Windows 7 operating system, Intel(R) Core(TM) i7 3.40 GHz processor and 8GB Random Access Memory (RAM). 


\section{Results}

\section{1}

\section{Results obtained by optimization}

The GA is configured through the Matlab®R2016b software. The optimization function within the GA called "gaoptimset" is used to configure the information of the genetic operators. In the simulation process a graph is generated representing the efficiency of the GA as a function of the number of cycles or generations. This plot is shown in Figure 5.1. As the number of generations increases, the losses are reduced. However, a point is reached from which the total losses remain constant, independent of the number of generations. The optimization process ended when it reached the maximum of generations configured. In Figure 5.1, the mean values (diamond blue) are the average among the best individuals (square black) of each generation. According to this result, 20 generations in the GA are enough to minimize the losses.

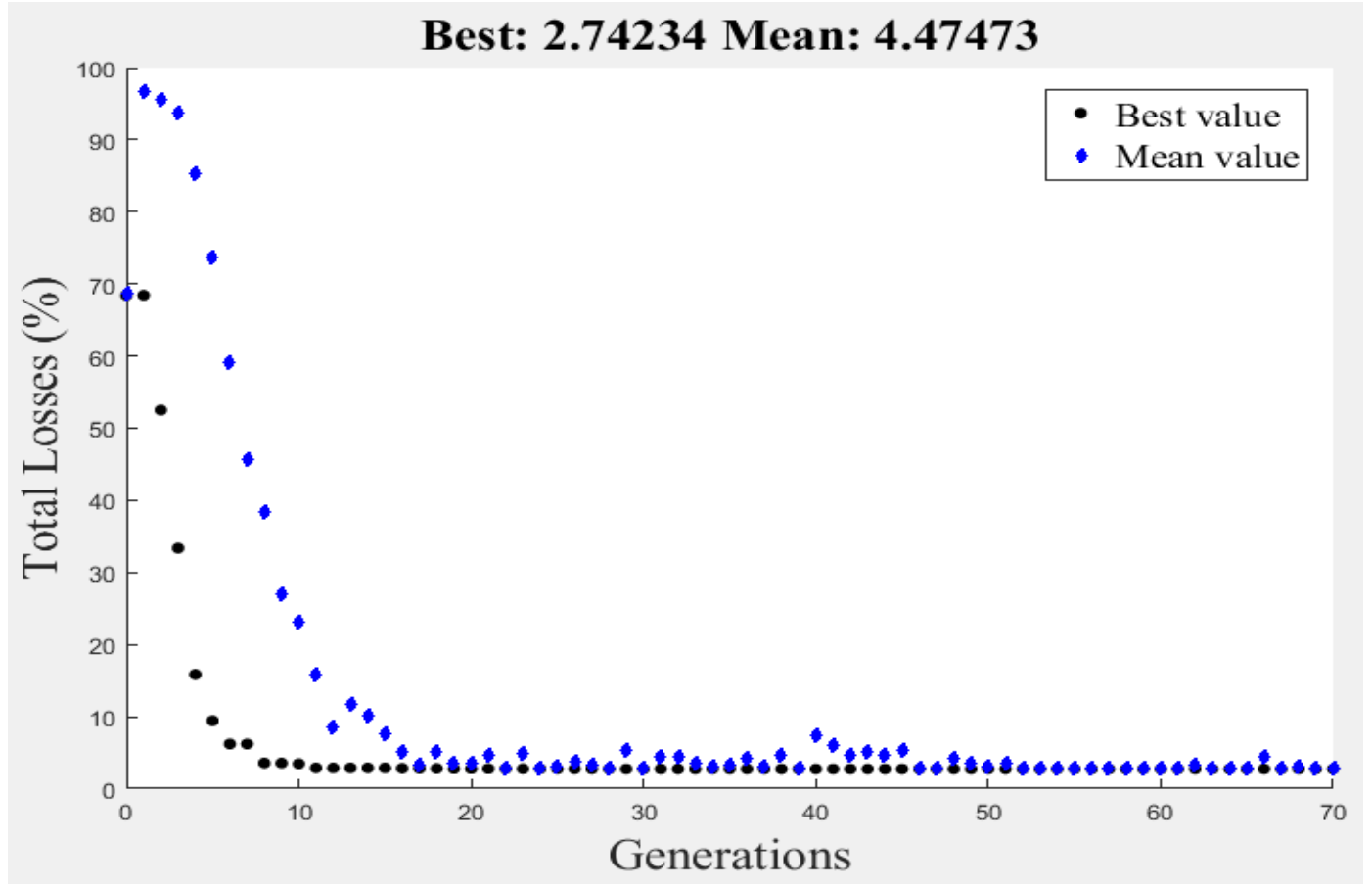

Figure 5.1: Genetic algorithm efficiency graph for rectangular contact mesh. 
To check the solution, we performed the optimization process 10 times, obtaining the same response in each of the simulations. We can see in Figure 5.1 the rapid convergence of the solution, to check the convergence of the solution we simulated the GA again, but this time increasing the mutation rate by $0.5 \%$ to reach $5 \%$. The results of these tests revealed that the response obtained by the GA is the optimal solution since after increasing the population diversity the algorithm converges to the same value.

The population and number of generations determine the number of GA evaluations, in our case 8400 evaluations. The optimization process time until obtaining an optimal response was approximately 8 hours, this time also depends on the data processing speed of the computer used.

Table 5.1 presents the results obtained with the GA for the construction parameters of the collecting finger mesh in the rectangular geometry used in the front contact of solar cells and a summary of the losses in the simulated situation. In addition, the values for the manufactured device, taken as a reference for the study are presented. For the calculation of the total losses, a very high parallel resistance $R_{S H}=68 \mathrm{k} \Omega$ was used, a value obtained experimentally. It can be seen that the total losses are greatly reduced from 5.03 to $2.74 \%$ for the optimized configuration.

Table 5.1: Comparison of grid data for the fabricated cell and for a cell using the optimal grid dimensions obtained by the GA.

\begin{tabular}{lrr} 
Parameter & $\begin{array}{c}\text { Fabricated } \\
\text { Solar Cell }\end{array}$ & GA response \\
\hline$d(\mu \mathrm{m})$ & 15.00 & 5.00 \\
$h(\mu \mathrm{m})$ & 0.215 & 2.00 \\
$n_{f}(\mathrm{units})$ & 4 & 7 \\
$X_{0}(\%)$ & 2.00 & 1.17 \\
$X_{R}(\%)$ & 3.09 & 1.59 \\
$X(\%)$ & $\mathbf{5 . 0 3}$ & $\mathbf{2 . 7 4}$ \\
\hline
\end{tabular}

With the new parameters obtained by GA, we obtained the new resistance values, according to equations $2-8$ to $2-12$. The data obtained are shown in Table 5.2, where we can observe a considerable reduction in $R_{S}$.

Looking closely at Tables 5.1 and 5.2, we notice that the optimal value obtained for $d$ is the imposed lower limit. This causes shadowing losses to be reduced, since the quantity $d \cdot n_{f}$ for the GA configuration is lower than that of the fabricated cell. Although this value of $d$ generates an increase in the front electrical resistance, since this contribution is negligible for the total resistance, the total losses of the objective function are little affected. The value 
Table 5.2: Comparison of grid data for the fabricated cell and for a cell using the optimal grid dimensions obtained by the GA.

\begin{tabular}{lrr}
\multicolumn{1}{c}{ Parameter } & $\begin{array}{r}\text { Fabricated } \\
\text { Solar Cell }\end{array}$ & GA response \\
\hline$R_{\text {metal }}(\Omega)$ & 5.21 & 1.00 \\
$R_{\text {emitter }}(\Omega)$ & 9.40 & 3.05 \\
$R_{\text {contact }}(\mu)$ & 9.22 & 27.00 \\
$R_{\text {back-contact }}(\mathrm{m} \Omega)$ & 5.55 & 5.55 \\
$R_{S}(\Omega)$ & $\mathbf{1 4 . 6 2}$ & $\mathbf{4 . 0 6}$ \\
\hline
\end{tabular}

of $h$ for the optimized setting has reached the upper limit. Since this factor has a low influence on shadowing and the thicker the metal collector finger, the lower the electrical resistance, it is natural that this limit optimizes this geometry, because as shown in Table 5.3, as $h$ increases, the losses decrease. The reduction in the resistance of the emitter is a consequence of the reduction of the distance traveled by the electrons in the emitter until they reach a metallic finger collector. Finally, the value optimized for $n_{f}$ respects the compromise between optical and electrical optimization. In Table 5.3 we can also see an improvement of $45.50 \%$ in relation to the configuration of the manufactured device.

Table 5.3: Results obtained by GA for the construction parameters of the collecting fingers with variation of the maximum height limit.

\begin{tabular}{lccccc} 
& Fabricated & \multicolumn{4}{c}{ GA response } \\
\cline { 3 - 6 } & $\begin{array}{c}\text { Polar cell } \\
h=0.215 \mu \mathrm{m}\end{array}$ & $h=0.215 \mu \mathrm{m}$ & $h=0.5 \mu \mathrm{m}$ & $h=1 \mu \mathrm{m}$ & $h=2 \mu \mathrm{m}$ \\
\hline$d(\mu \mathrm{m})$ & 15.00 & 5.00 & 5.00 & 5.00 & 5.00 \\
$n_{f}($ units $)$ & 4 & 9 & 8 & 7 & 7 \\
$X_{o}(\%)$ & 2.00 & 1.5 & 1.33 & 1.17 & 1.17 \\
$X_{R}(\%)$ & 3.09 & 2.26 & 1.84 & 1.73 & 1.59 \\
$X(\%)$ & 5.03 & 3.72 & 3.14 & 2.87 & $\mathbf{2 . 7 4}$ \\
Reduction & 0 & 26.00 & 37.60 & 42.90 & $\mathbf{4 5 . 5 0}$ \\
in losses (\%) & 0 & & & & \\
\hline
\end{tabular}

\section{2}

\section{Applications of optimization by genetic algorithm to other geometries}

So far we have talked about the optimization of front contacts with geometry in the form of comb or rectangular grid. In this work we also made variations in the geometry of the metal grid. The objective is to observe the behavior of the total losses of the solar cell, trying to get the most optimal 
solution. The two geometries of front contacts chosen for testing are hexagonal and diamond. A general scheme of all the geometries to be optimized can be seen in Figure 5.2. For each geometry type, a simulator must be programmed with specific characteristics of the geometry, since the resistance and shadowing generated by each geometry are different. A study of the equations is made and the respective changes are applied depending on the geometry to be optimized. A validation test is made to each simulator before being part of the optimization system.

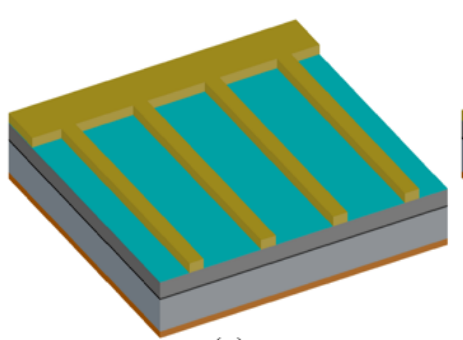

(a)

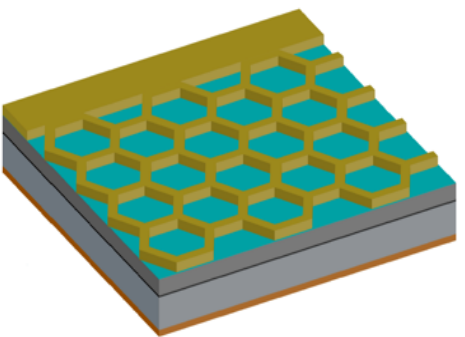

(b)

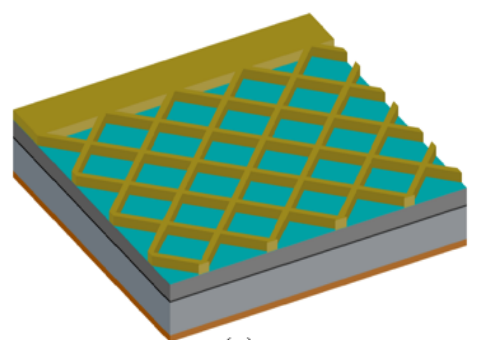

(c)

Figure 5.2: Scheme of the geometries to be optimized. (a) rectangular structure, (b) hexagonal structure, (c) diamond structure.

Rectangular geometry for the construction of the collecting fingers is, in fact, the easiest to produce. However, other geometries can be used and could result in greater conversion efficiencies for the PV device. Another reason for test other geometries is the high electrical resistance presented by the emitter in the rectangular configuration. With these tests we want to find shorter paths that reduce the distances that the majority carriers must travel to reach the collecting fingers.

In order to test this possibility, we have tried to simulate other geometries for the mesh of collecting fingers, such as the one of hexagonal structure, shown in Figure 5.3(a), and the one of diamond structure, shown in Figure 5.3(b). Using another geometric design can help reduce the distance traveled by the charges through the contacts. The meshes formed by these structures are represented next to the drawing that define the units of the collecting fingers. The parameters of interest for the optimization of the hexagonal and diamond structures are, as shown in Figures 5.3(a) and 5.3(b), respectively: the height $h$ of the metal and the difference $T$ between the circumscribed $R_{a}$ and inscribed $R_{b}$ radius that pass through the internal and external vertices of the figures, respectively, that is, $T=R_{a}-R_{b}$.

The equations that define the electrical resistances of the metal and emitter layers for the new configurations are slightly altered due to the new 


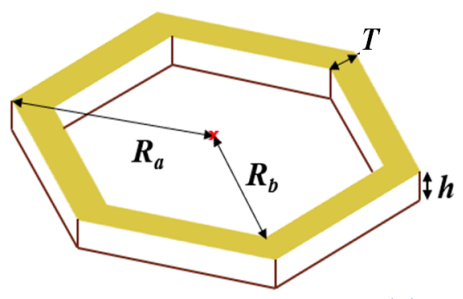

(a)
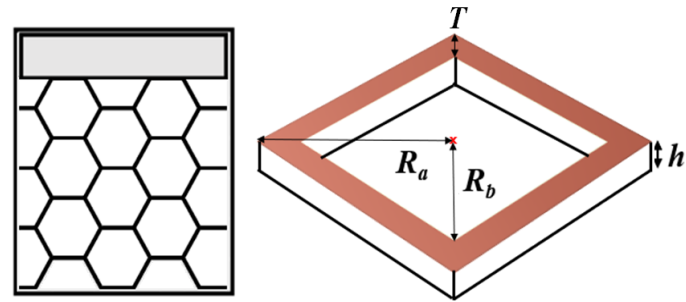

(b)

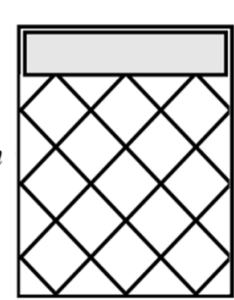

Figure 5.3: Examples of possible geometries for the collecting fingers: (a) hexagonal structure and (b) diamond structure.

geometry. The procedure for the calculation of equation 2-9 of the emitter layer is as follows:

In the hexagonal geometry the displacement of the majority carriers takes place from the center of the hexagon to its ends. We can see in Figure 5.4 a diagram of the hexagonal structure. The hexagonal structure can be divided into 6 equal triangles. We take one of the triangles to perform the calculations.

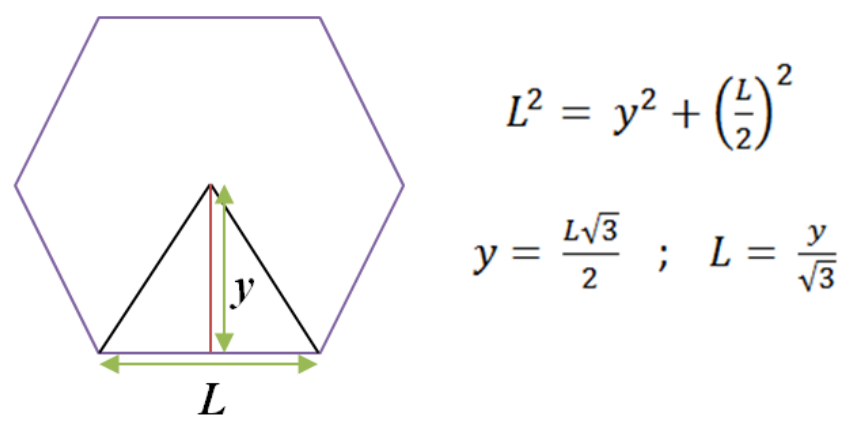

Figure 5.4: Diagram of a regular hexagon.

The equation that describes the flow of electric charge carriers, usually through a metallic cable or any other electrical conductor is:

$$
I=\int_{S} J \cdot d S
$$

Where $\mathrm{I}$ is the electric current, $\mathrm{J}$ is the current density and $\mathrm{S}$ is the studied surface. Knowing the current we can calculate the power losses, $P_{\text {loss }}$.

$$
\begin{gathered}
P_{\text {loss }}=\int I(y)^{2} d R \\
P_{\text {loss }}=\int_{0}^{\frac{L \sqrt{3}}{2}} J^{2}\left(\frac{L \cdot y}{2}\right)^{2}\left(\frac{\rho_{S} \cdot d y}{L}\right) \\
P_{\text {loss }}=\frac{\sqrt{3}}{6} J^{2} \rho_{S} \int_{0}^{\frac{L \sqrt{3}}{2}} y^{3} d y \\
P_{\text {loss }}=\frac{3 \sqrt{3}}{128} J^{2} \rho_{S} L^{4}
\end{gathered}
$$


With the power losses we can calculate the resistance of the part of the hexagon that was studied.

$$
\begin{gathered}
R_{3}{ }^{T R I}=\frac{P_{\text {loss }}}{I^{2}}=\frac{\frac{3 \sqrt{3}}{128} J^{2} \rho_{S} L^{4}}{(J L y)^{2}} \\
R_{3}{ }^{T R I}=\frac{\sqrt{3} \cdot \rho_{S}}{32}
\end{gathered}
$$

Since the behavior of the majority carriers is equal for the 6 triangle that make up the hexagon, the resistance equation of the emitter layer is as follows.

$$
R_{3}{ }^{H E X}=\frac{\sqrt{3} \cdot \rho_{S 3}}{(6 \cdot 32)}
$$

For the diamond structure the calculation is performed in the same way as for the hexagonal structure, the equation is as follows.

$$
R_{3}{ }^{D I A}=\frac{\sqrt{3} \cdot \rho_{S 3}}{(4 \cdot 16)}
$$

Equations 5-8 and 5-9 are the new equations that replace equation 2-9 for the hexagonal and diamond structures, respectively. Where the variables are the same as defined in equations 2-8 to 2-12. The final resistance of the settings continues to be calculated as in equation 2-13. The minimum and maximum values defined for the constructional parameters of these geometries, which are also the result of physical or technical limitations for the devices, are presented in Table 5.4. The GA configuration also has a restriction for these structures, the value of the circumscribed radius $R_{a}$ must be greater than the value of the parameter $T$, thus the algorithm excludes responses that slow down the optimization process and allows a more specific search space.

Table 5.4: Limit values for the parameters of the construction of the collector fingers in the hexagonal and diamond geometries.

\begin{tabular}{crr} 
Parameter & Lower Limit & Upper Limit \\
\hline$T(\mu \mathrm{m})$ & 5.00 & 1500 \\
$h(\mu \mathrm{m})$ & 0.10 & 2.00 \\
$R_{a}(\mu \mathrm{m})$ & 100 & 1500 \\
\hline
\end{tabular}

In the initial tests the number of generations was 70, after performing some tests the efficiency graph showed a sub-optimal response, i.e., the convergence of the solution was not ideal, so the number of generations was increased to 100, this change implies a long delivery time of the optimal response to increase, therefore the value of the population was reduced to 80, to have a acceptable delivery time. Figure(s) 5.5 and 5.6 shows the GA efficiency graph for hexagonal and diamond structures. 


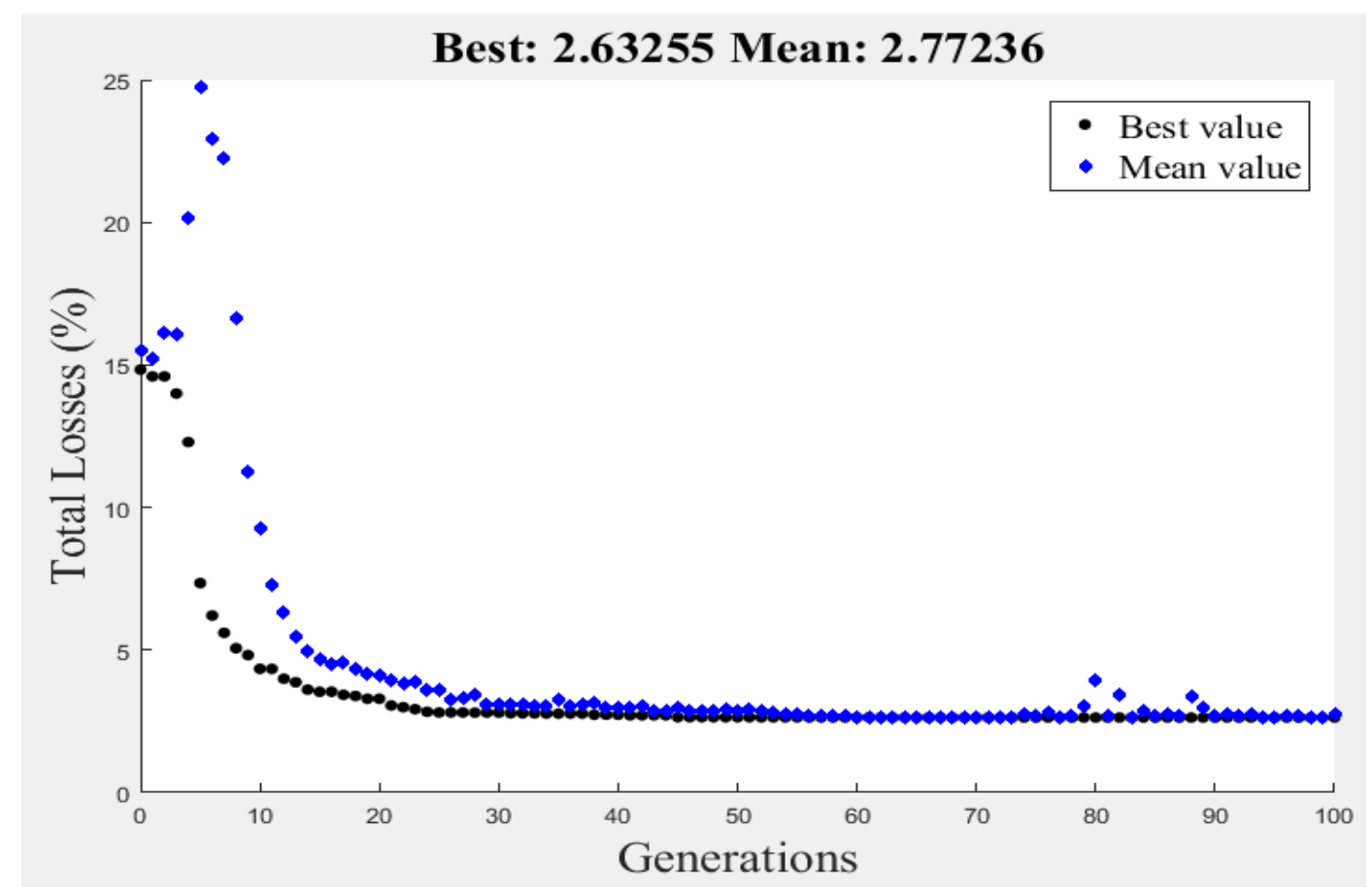

Figure 5.5: Genetic algorithm efficiency graph for hexagonal contact mesh.

Tables 5.5 and 5.6 present the optimized results for the parameters of the construction of the collecting fingers on the hexagonal and diamond geometries, respectively, obtained by GA.

Table 5.5: Results obtained by GA for the construction parameters of the collecting fingers with hexagonal geometry with variation of the maximum limit of its height.

\begin{tabular}{lccccc} 
& Fabricated & \multicolumn{4}{c}{ GA response } \\
\cline { 3 - 6 } Parameter & $\begin{array}{c}\text { solar cell } \\
h=0.215 \mu \mathrm{m}\end{array}$ & $h=0.215 \mu \mathrm{m}$ & $h=0.5 \mu \mathrm{m}$ & $h=1 \mu \mathrm{m}$ & $h=2 \mu \mathrm{m}$ \\
\hline$T(\mu \mathrm{m})$ & $\mathrm{NA}$ & 7.62 & 7.13 & 5.64 & 5.00 \\
$R_{a}(\mu \mathrm{m})$ & $\mathrm{NA}$ & 327 & 418 & 498 & 599 \\
$X_{o}(\%)$ & 2.00 & 2.19 & 1.69 & 1.32 & 1.00 \\
$X_{R}(\%)$ & 3.09 & 2.35 & 1.88 & 1.75 & 1.64 \\
$X(\%)$ & 5.03 & 4.48 & 3.58 & 3.02 & $\mathbf{2 . 6 3}$ \\
$\begin{array}{l}\text { Reduction } \\
\text { in losses }(\%)\end{array}$ & 0 & 10.93 & 28.83 & 39.96 & $\mathbf{4 7 . 7 1}$ \\
\hline
\end{tabular}

During the optimization process of each of the geometries, the GA selects the maximum height limit as the optimal parameter. The greater the height, the greater reduction in total losses is achieved. Therefore, the height of the collector fingers is important in the optimization process. This parameter must be taken into account in the manufacture of solar cells. The output of the 


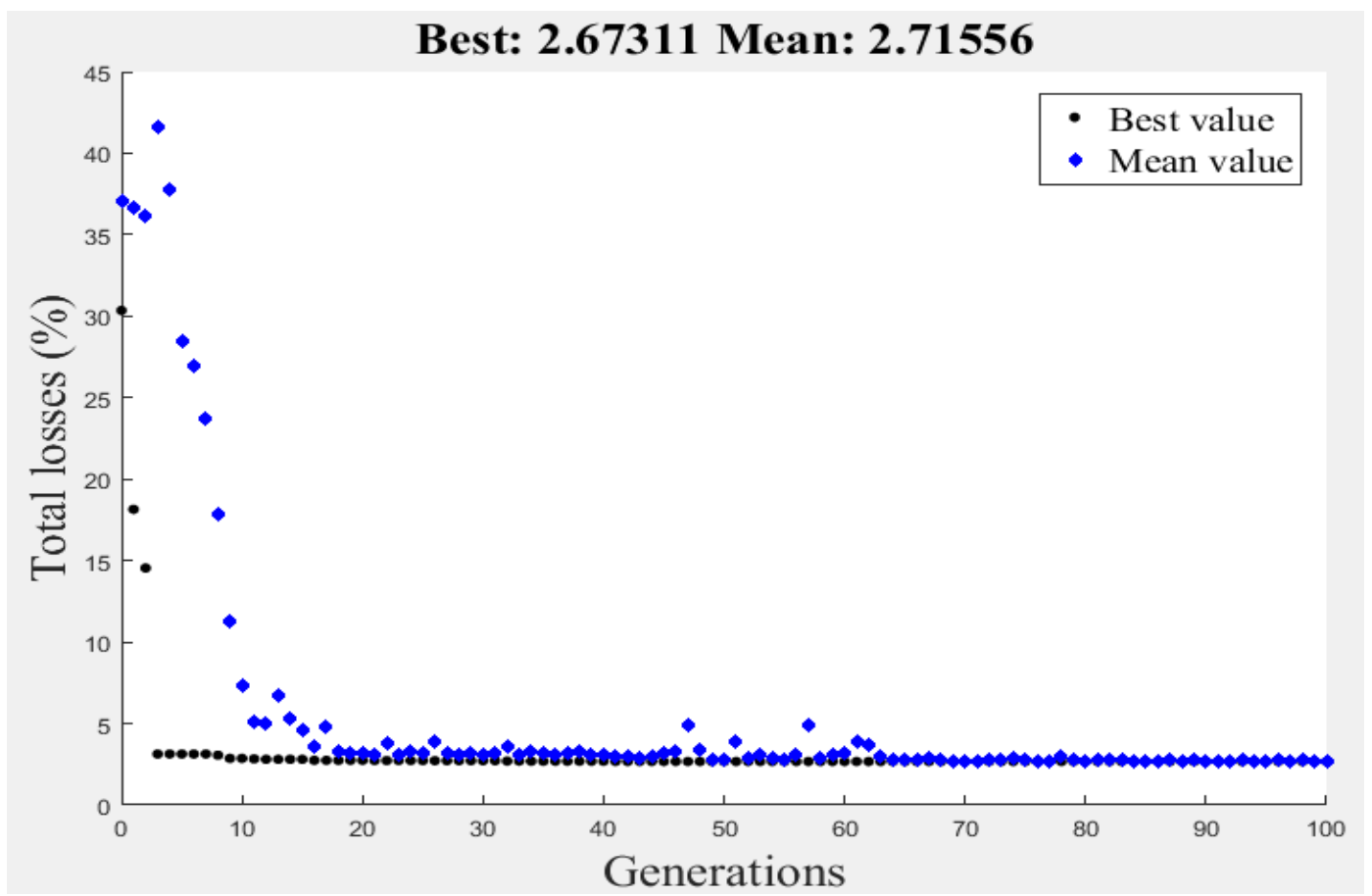

Figure 5.6: Genetic algorithm efficiency graph for diamond contact mesh.

Table 5.6: Results obtained by GA for the construction parameters of the collecting fingers with diamond geometry with variation of the maximum height limit.

\begin{tabular}{lccccc} 
& Fabricated & \multicolumn{4}{c}{ GA response } \\
\cline { 3 - 6 } & $\begin{array}{c}\text { solar cell } \\
h=0.215 \mu \mathrm{m}\end{array}$ & $h=0.215 \mu \mathrm{m}$ & $h=0.5 \mu \mathrm{m}$ & $h=1 \mu \mathrm{m}$ & $h=2 \mu \mathrm{m}$ \\
\hline$T(\mu \mathrm{m})$ & $\mathrm{NA}$ & 8.01 & 6.52 & 6.11 & 5.31 \\
$R_{a}(\mu \mathrm{m})$ & $\mathrm{NA}$ & 332 & 397 & 423 & 519 \\
$X_{o}(\%)$ & 2.00 & 1.44 & 1.35 & 1.25 & 1.01 \\
$X_{R}(\%)$ & 3.09 & 2.38 & 1.99 & 1.69 & 1.68 \\
$X(\%)$ & 5.03 & 3.78 & 3.31 & 2.91 & $\mathbf{2 . 6 7}$ \\
$\begin{array}{l}\text { Reduction } \\
\text { in losses }(\%)\end{array}$ & 0 & 24.85 & 34.19 & 42.15 & $\mathbf{4 6 . 7 2}$ \\
\hline
\end{tabular}

optimization process of each of the geometries are the parameters optimized with these new dimensions. With equations 2-8 to $2-12,5-8$ and 5-9 we can calculate the resistances of each layer for each of the geometries tested. The obtained resistance values are in Table 5.7.

By making a comparison of the resistance of the different layers of each of the geometries with the reference solar cell, there is a significant reduction in the resistances. The metal resistance value is smaller in the rectangular geometry compared to the other geometries because the finger width is greater. The hexagonal geometry presents a greater reduction in the emitter resistance, 
Table 5.7: Electrical resistance of each layer and total in the manufactured solar cell and those obtained by GA for the geometries tested.

\begin{tabular}{lcccc}
\multirow{2}{*}{ Parameter } & Fabricated & \multicolumn{3}{c}{ GA response, $h=2 \mu \mathrm{m}$} \\
\cline { 3 - 5 } & $\begin{array}{c}\text { solar cell } \\
h=0.215 \mu \mathrm{m}\end{array}$ & $\begin{array}{c}\text { rectangular } \\
\text { geometry }\end{array}$ & $\begin{array}{c}\text { hexagonal } \\
\text { geometry }\end{array}$ & $\begin{array}{c}\text { diamond } \\
\text { geometry }\end{array}$ \\
\hline$R_{\text {metal }}(\Omega)$ & 5.21 & 1.00 & 2.76 & 2.26 \\
$R_{\text {emitter }}(\Omega)$ & 9.40 & 3.05 & 1.70 & 2.34 \\
$R_{\text {contact }}(\mu)$ & 9.22 & 27.00 & 8.27 & 2.68 \\
$R_{\text {back-contact }}(\mathrm{m} \Omega)$ & 5.55 & 5.55 & 5.55 & 5.55 \\
$R_{S}(\Omega)$ & $\mathbf{1 4 . 6 4}$ & $\mathbf{4 . 0 6}$ & 4.47 & 4.31 \\
\hline
\end{tabular}

due to the smaller distance to be covered by the electrons before being collected by the fingers. However, there is an increase in the metal resistance because of the increase in length of the collecting finger. The total resistance $R_{S}$ is smaller in the rectangular geometry. However, as we shall see, this is not necessarily the ideal structure because we must still bring the shadowing into account.

Figure 5.7 shows a diagram of the structure of the front contacts optimized for each of the geometries tested and Table 5.8 summarizes the results obtained from the optimization process of the three geometries. By analyzing it, it is possible to compare the final results associated with the losses and to evaluate the best geometry. In Table 5.8, it can be seen that all the percentages of loss, both by shadowing and by resistance, are lower than in the manufactured solar cell. It is also noticed that the percentage of shadowing losses obtained by the GA with the hexagonal geometry is the lowest in comparison with the other two geometries, but the percentage of losses by resistance is greater than that obtained with a rectangular structure and smaller than the one obtained with a diamond structure. With respect to the total losses, a better relation between shadowing and resistance in the hexagonal configuration is obtained, which leads to a good decrease in the percentage of total losses.

Table 5.8: Best results obtained by GA for the geometries tested.

\begin{tabular}{lcccc} 
& Fabricated & \multicolumn{3}{c}{ GA response, $h=2 \mu \mathrm{m}$} \\
\cline { 3 - 5 } & solar cell & rectangular & hexagonal & diamond \\
& $h=0.215 \mu \mathrm{m}$ & geometry & geometry & geometry \\
\hline$X_{o}(\%)$ & 2.00 & 1.17 & 1.00 & 1.01 \\
$X_{R}(\%)$ & 3.09 & 1.59 & 1.64 & 1.68 \\
$X(\%)$ & 5.03 & 2.74 & $\mathbf{2 . 6 3}$ & 2.67 \\
Reduction & & 45.53 & $\mathbf{4 7 . 7 1}$ & 46.72 \\
in losses $(\%)$ & 0 & & & \\
\hline
\end{tabular}




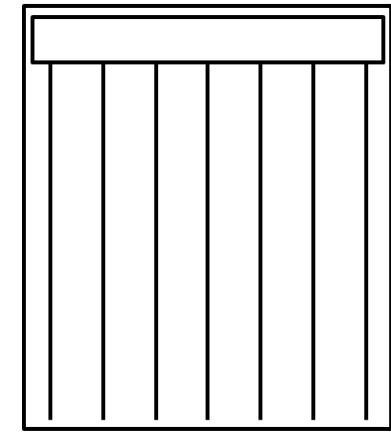

(a)

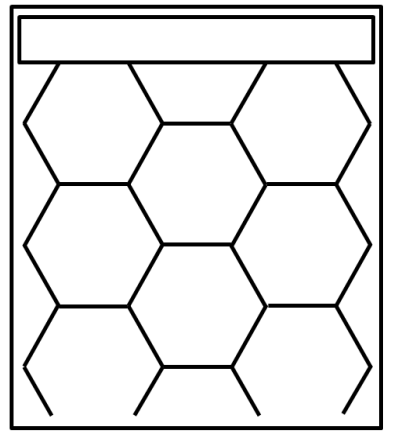

(b)

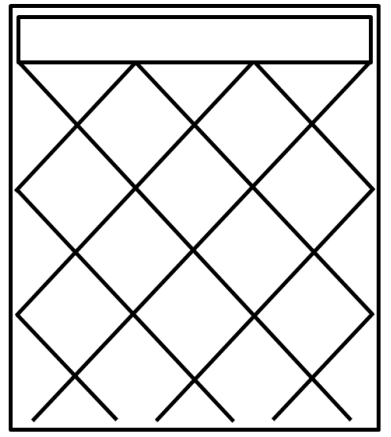

(c)

Figure 5.7: Diagram of the front contacts for each of the optimized geometries, for $h=2 \mu \mathrm{m}$ : (a) rectangular structure (b) hexagonal structure (c) diamond structure.

\section{3}

\section{Test results with variation in the size of the solar cell}

The code programmed to be the objective function has other parameters that can become variables, the size of the total solar cell is one of those parameters, the variation of those dimensions directly affects the behavior of the total losses. There is a possibility of finding a better result.

The results of the optimization that has been carried out so far are based on $I V$ curve and the characteristics of a fabricated solar cell of size of $3 \times 3 \mathrm{~mm}$. We will carry out the same procedure for a manufactured solar cell of size of 2x2 $\mathrm{mm}$ and another of $5 \times 5 \mathrm{~mm}$. Figure 5.8 shows the top view and the structure configuration of the solar cells of size $2 \times 2 \mathrm{~mm}, 3 \times 3 \mathrm{~mm}$ and $5 \times 5 \mathrm{~mm}$.

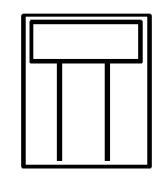

(a)

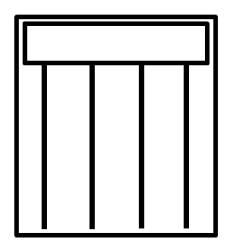

(b)

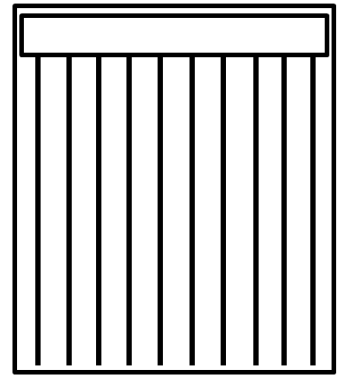

(c)

Figure 5.8: Top view and the configuration of the fabricated solar cells: (a) size $2 \times 2 \mathrm{~mm}$ with 2 fingers, (b) size $3 \times 3 \mathrm{~mm}$ with 4 fingers (c) size $5 \times 5 \mathrm{~mm}$ with 10 fingers.

In Figure 5.9, the experimental $I V$ curves used in this work can be observed. The parameters that will be optimized for 3 geometries are the same, for the case of the rectangular structure: $d, h, n_{f}$, and for the case 
of the hexagonal and diamond structures: $T, h, R_{a}$. Due to the increase in the size of the solar cells to be tested, the limits of variation of the parameters chosen for the optimization must change taking into account the limits for manufacturing of this devices. The new limits must be configured in the GA and then proceed to the execution of the optimization process.

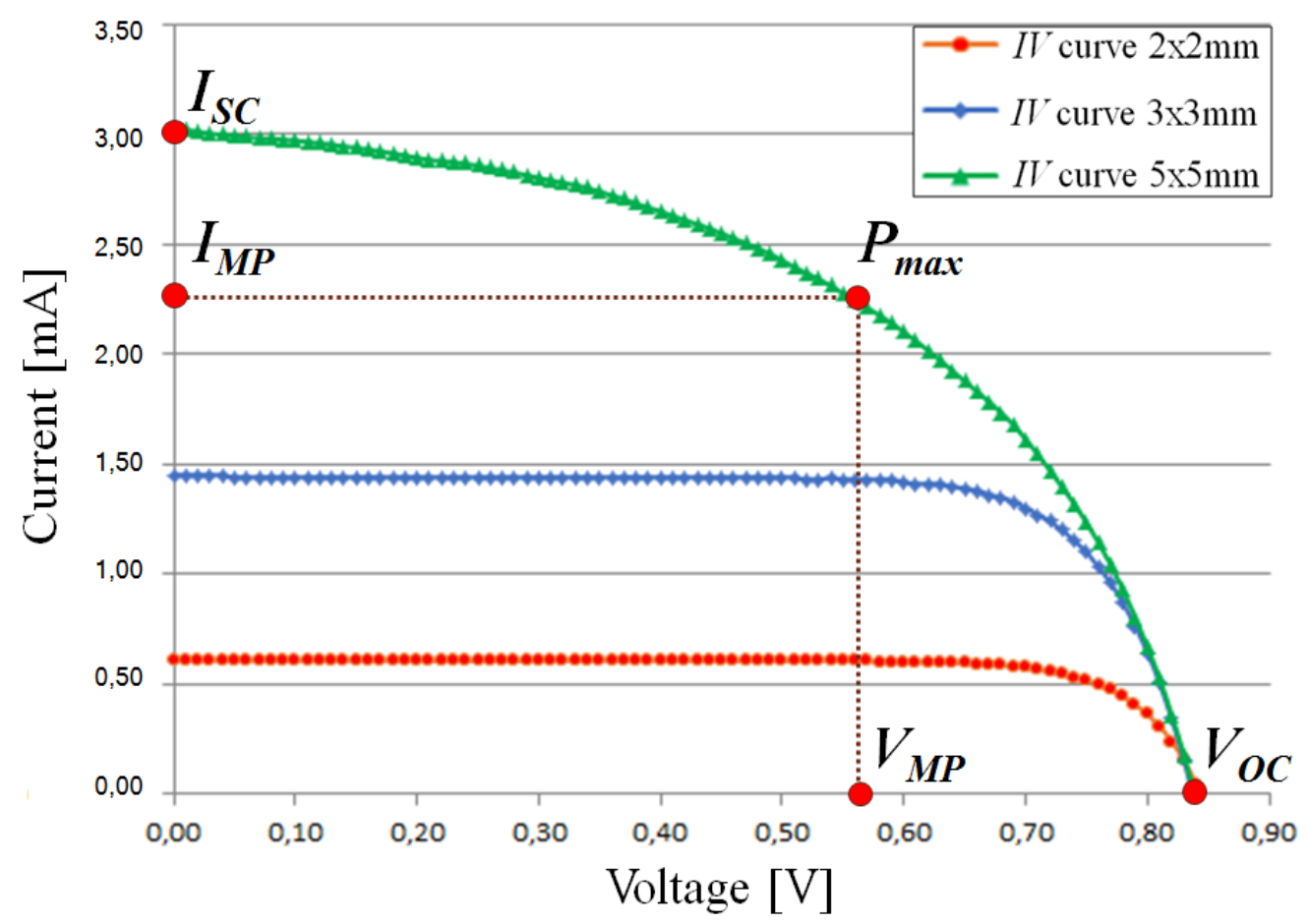

Figure 5.9: Curves $I V$ characteristics of the solar cells manufactured. The green curve represents a solar cell of size $5 \times 5 \mathrm{~mm}$, the blue curve represents a solar cell of size $3 \times 3 \mathrm{~mm}$ and the red curve represents a solar cell of size $3 \times 3 \mathrm{~mm}$.

Results for rectangular structure: After performing the optimization procedure for the rectangular structure, the results obtained for a solar cell of size $2 \times 2 \mathrm{~mm}$ were recorded in Table 5.9, where we can observe that the width of the collector's finger remains constant after the GA execution with 4 different height limits, the GA selects the imposed limit for $d$ as the optimal parameter. With respect to the number of fingers the value was increased from 2 to 4 for the best response obtained by the GA, the small size of the solar cell limits the variation of this parameter. The best result for total losses obtained by the GA was $3.99 \%$, which leads to a reduction in losses of $37.85 \%$ with respect to the total losses of the solar cell manufactured.

The data obtained after the optimization of the solar cell of size $5 \times 5 \mathrm{~mm}$ are recorded in Table 5.10, here we can see that the width of the collector's finger continues to remain constant after the execution of GA with 4 different height limits, again selects the imposed limit for $d$ as the optimal parameter. 
Table 5.9: Results obtained by GA for rectangular structure with variation of the maximum height limit for a solar cell of size $2 \times 2 \mathrm{~mm}$.

\begin{tabular}{lccccc} 
& Fabricated & \multicolumn{4}{c}{ GA response } \\
\cline { 3 - 6 } & $\begin{array}{c}\text { solar cell } \\
n=0.215 \mu \mathrm{m}\end{array}$ & $h=0.215 \mu \mathrm{m}$ & $h=0.5 \mu \mathrm{m}$ & $h=1 \mu \mathrm{m}$ & $h=2 \mu \mathrm{m}$ \\
\hline$d(\mu \mathrm{m})$ & 15.00 & 5.00 & 5.00 & 5.00 & 5.00 \\
$n_{f}(\mathrm{units})$ & 2.00 & 5.00 & 5.00 & 4.00 & 4.00 \\
$X_{o}(\%)$ & 1.50 & 1.25 & 1.25 & 1.00 & 1.00 \\
$X_{R}(\%)$ & 4.99 & 3.25 & 2.97 & 3.09 & 3.02 \\
$X(\%)$ & 6.42 & 4.46 & 4.18 & 4.06 & $\mathbf{3 . 9 9}$ \\
Reduction & 0 & 30.53 & 34.89 & 36.76 & $\mathbf{3 7 . 8 5}$ \\
in losses $(\%)$ & & & & & \\
\hline
\end{tabular}

The number of collector fingers of the solar cell manufactured is 10, the optimal parameter obtained by the GA is 11 , the size of this solar cell allows greater variation of this parameter. A considerable reduction in the percentage of resistance and shadowing losses can be seen. The greatest minimization of total losses obtained by the GA was $2.27 \%$, which leads to a reduction in losses of $54.42 \%$ with respect to the total losses of the solar cell manufactured.

Table 5.10: Results obtained by GA for rectangular structure with variation of the maximum height limit for a solar cell of size $5 \times 5 \mathrm{~mm}$.

\begin{tabular}{lccccc} 
& Fabricated & \multicolumn{4}{c}{ GA response } \\
\cline { 3 - 6 } & $\begin{array}{c}\text { solar cell } \\
h=0.215 \mu \mathrm{m}\end{array}$ & $h=0.215 \mu \mathrm{m}$ & $h=0.5 \mu \mathrm{m}$ & $h=1 \mu \mathrm{m}$ & $h=2 \mu \mathrm{m}$ \\
\hline$d(\mu \mathrm{m})$ & 15.00 & 5.00 & 5.00 & 5.00 & 5.00 \\
$n_{f}$ (units) & 10.00 & 20.00 & 15.00 & 12.00 & 11.00 \\
$X_{o}(\%)$ & 3.00 & 2.00 & 1.50 & 1.20 & 1.10 \\
$X_{R}(\%)$ & 2.04 & 2.24 & 1.63 & 1.39 & 1.19 \\
$X(\%)$ & 4.98 & 4.20 & 3.10 & 2.57 & $\mathbf{2 . 2 7}$ \\
Reduction & 0 & 15.66 & 37.75 & 48.39 & $\mathbf{5 4 . 4 2}$ \\
in losses (\%) & 0 & & & & \\
\hline
\end{tabular}

Results for Hexagonal structure: Table 5.11 shows the results of the optimization for a solar cell of size $2 \times 2 \mathrm{~mm}$ with a hexagonal structure, where it can be seen that the parameter $\mathrm{T}$ increases at the same time as the parameter $\mathrm{h}$ decreases. With respect to the Ra parameter, it decreases as the height $\mathrm{h}$ decreases. In the case of the total losses for a hexagonal structure and size $2 \times 2 \mathrm{~mm}$, the best result obtained by the GA was $3.72 \%$, which leads to a reduction in losses of $42.05 \%$ with respect to the total losses of the solar cell manufactured. 
Table 5.11: Results obtained by GA for the hexagonal structure with variation of the maximum height limit for a solar cell of size $2 \times 2 \mathrm{~mm}$.

\begin{tabular}{lccccc} 
& Fabricated & \multicolumn{4}{c}{ GA response } \\
\cline { 3 - 6 } & $\begin{array}{c}\text { solar cell } \\
h=0.215 \mu \mathrm{m}\end{array}$ & $h=0.215 \mu \mathrm{m}$ & $h=0.5 \mu \mathrm{m}$ & $h=1 \mu \mathrm{m}$ & $h=2 \mu \mathrm{m}$ \\
\hline$T(\mu \mathrm{m})$ & $\mathrm{NA}$ & 5.80 & 5.09 & 5.00 & 5.00 \\
$R_{a}(\mu \mathrm{m})$ & $\mathrm{NA}$ & 306 & 373 & 373 & 400 \\
$X_{o}(\%)$ & 1.50 & 1.60 & 1.35 & 1.34 & 1.13 \\
$X_{R}(\%)$ & 4.99 & 3.11 & 2.88 & 2.70 & 2.62 \\
$X(\%)$ & 6.42 & 4.66 & 4.19 & 4.00 & $\mathbf{3 . 7 2}$ \\
Reduction & 0 & 27.71 & 34.74 & 37.69 & $\mathbf{4 2 . 0 5}$ \\
in losses $(\%)$ & & & & & \\
\hline
\end{tabular}

The results obtained after the optimization of the solar cell with a hexagonal structure of size $5 \times 5 \mathrm{~mm}$ are recorded in Table 5.12, here we can see that the parameter of width, $T$, increases while the height parameter decreases. In the case of the parameter, Ra, decreases when the height decreases. When the height parameter is $0.25 \mu \mathrm{m}$, we can see that the percentage of total losses of the response obtained by the GA does not exceed the value of the solar cell manufactured, the GA finds an optimal value with respect to the percentage of losses by shadowing, but with respect to the losses due to the resistance, the losses obtained by GA are greater compared to the solar cell manufactured. It is the first time that a GA response does not exceed the value to be optimized. We can say that height plays an important role since when $h=2 \mu$ m there is a considerable reduction in the percentage of resistance and shading losses, which leads to a high reduction in the percentage of total losses. The greatest minimization of the total losses obtained by the GA was $2.84 \%$, which leads to a reduction of losses of $42.97 \%$ with respect to the total losses of the manufactured solar cell.

Results for diamond structure: Table 5.13 shows the results of the optimization for a solar cell of size $2 \times 2 \mathrm{~mm}$ with a diamond structure, where we can see that the parameter $T$ remained constant for $h=2 \mu \mathrm{m}$ and $h=$ $1 \mu \mathrm{m}$ but when the height continues decreasing the parameter $\mathrm{T}$ begins to increase as in the hexagonal geometry. With respect to the parameter $R_{a}$, it has the same behavior for $h=2 \mu \mathrm{m}$ and $h=1 \mu \mathrm{m}, R_{a}$ remains constant, but for smaller heights, the value of $R_{a}$ decreases. In the case of the total losses for a diamond structure and size $2 \times 2 \mathrm{~mm}$, the best result obtained by the GA was $3.56 \%$, which leads to a reduction in losses of $44.55 \%$ with respect to the total losses of the manufactured solar cell.

The results obtained after the optimization of the solar cell with a 
Table 5.12: Results obtained by GA for the hexagonal structure with variation of the maximum height limit for a solar cell of size $5 \times 5 \mathrm{~mm}$.

\begin{tabular}{lccccc} 
& Fabricated & \multicolumn{4}{c}{ GA response } \\
\cline { 3 - 6 } & $\begin{array}{c}\text { solar cell } \\
h=0.215 \mu \mathrm{m}\end{array}$ & $h=0.215 \mu \mathrm{m}$ & $h=0.5 \mu \mathrm{m}$ & $h=1 \mu \mathrm{m}$ & $h=2 \mu \mathrm{m}$ \\
\hline$T(\mu \mathrm{m})$ & $\mathrm{NA}$ & 12.03 & 10.84 & 9.29 & 7.75 \\
$R_{a}(\mu \mathrm{m})$ & $\mathrm{NA}$ & 410 & 460 & 527 & 661 \\
$X_{o}(\%)$ & 3.00 & 2.83 & 2.40 & 2.03 & 1.53 \\
$X_{R}(\%)$ & 2.04 & 2.81 & 1.78 & 1.42 & 1.34 \\
$X(\%)$ & 4.98 & 5.56 & 4.13 & 3.43 & $\mathbf{2 . 8 4}$ \\
Reduction & 0 & -11.64 & 17.07 & 31.12 & $\mathbf{4 2 . 9 7}$ \\
in losses $(\%)$ & & & & & \\
\hline
\end{tabular}

Table 5.13: Results obtained by GA for the diamond structure with variation of the maximum height limit for a solar cell of size $2 \times 2 \mathrm{~mm}$.

\begin{tabular}{lccccc} 
& Fabricated & \multicolumn{4}{c}{ GA response } \\
\cline { 3 - 6 } & $\begin{array}{c}\text { solar cell } \\
h=0.215 \mu \mathrm{m}\end{array}$ & $h=0.215 \mu \mathrm{m}$ & $h=0.5 \mu \mathrm{m}$ & $h=1 \mu \mathrm{m}$ & $h=2 \mu \mathrm{m}$ \\
\hline$T(\mu \mathrm{m})$ & $\mathrm{NA}$ & 5.57 & 5.06 & 5.27 & 5.27 \\
$R_{a}(\mu \mathrm{m})$ & $\mathrm{NA}$ & 341 & 332 & 335 & 335 \\
$X_{o}(\%)$ & 1.50 & 1.08 & 1.04 & 0.96 & 0.96 \\
$X_{R}(\%)$ & 4.99 & 3.29 & 2.88 & 2.71 & 2.63 \\
$X(\%)$ & 6.42 & 4.33 & 3.89 & 3.64 & $\mathbf{3 . 5 6}$ \\
Reduction & 0 & 32.55 & 39.41 & 43.30 & $\mathbf{4 4 . 5 5}$ \\
in losses $(\%)$ & & & & & \\
\hline
\end{tabular}

diamond structure of size $5 \times 5 \mathrm{~mm}$ are recorded in Table 5.14, here we can see that the parameter, $T$, increases while the height parameter decreases. In the case of the parameter, Ra, decreases when the height decreases. A considerable reduction in total losses was obtained. The greatest minimization of the total losses obtained by the GA was $2.64 \%$, which leads to a $46.98 \%$ loss reduction with respect to the total losses of the manufactured solar cell.

During the simulation process it is observed that the best results were obtained for a frontal contact structure of height $h=2 \mu \mathrm{m}$, therefore in Table 5.15 , the results of the optimization will be presented only for this height. Table 5.15 summarizes the results obtained from the optimization process of the three geometries for a solar cell of size $2 \times 2 \mathrm{~mm}$. It is possible to compare the final results associated with the losses and evaluate the best geometry, in Figure 5.10 we have a better visualization of these results.

In Figure 5.10, we can be seen that each of the geometries obtained a considerable reduction in the total losses, the percentage of total losses 
Table 5.14: Results obtained by GA for the diamond structure with variation of the maximum height limit for a solar cell of size $5 \times 5 \mathrm{~mm}$.

\begin{tabular}{lccccc} 
& Fabricated & \multicolumn{4}{c}{ GA response } \\
\cline { 3 - 6 } & $\begin{array}{c}\text { Polar cell } \\
h=0.215 \mu \mathrm{m}\end{array}$ & $h=0.215 \mu \mathrm{m}$ & $h=0.5 \mu \mathrm{m}$ & $h=1 \mu \mathrm{m}$ & $h=2 \mu \mathrm{m}$ \\
\hline$T(\mu \mathrm{m})$ & $\mathrm{NA}$ & 13.67 & 10.51 & 8.63 & 8.68 \\
$R_{a}(\mu \mathrm{m})$ & $\mathrm{NA}$ & 364 & 450 & 573 & 551 \\
$X_{o}(\%)$ & 3.00 & 2.58 & 1.98 & 1.54 & 1.43 \\
$X_{R}(\%)$ & 2.04 & 2.37 & 1.89 & 1.75 & 1.23 \\
$X(\%)$ & 4.98 & 4.88 & 3.84 & 3.27 & $\mathbf{2 . 6 4}$ \\
$\begin{array}{l}\text { Reduction } \\
\text { in losses (\%) }\end{array}$ & 0 & 2.01 & 22.89 & 34.34 & $\mathbf{4 6 . 9 8}$ \\
\hline
\end{tabular}

Table 5.15: The best results obtained by GA for the geometries tested, size of the solar cell $2 \times 2 \mathrm{~mm}$.

\begin{tabular}{lcccc} 
& Fabricated & \multicolumn{3}{c}{ GA response, $h=2 \mu \mathrm{m}$} \\
\cline { 3 - 5 } & $\begin{array}{c}\text { solar cell } \\
h=0.215 \mu \mathrm{m}\end{array}$ & $\begin{array}{c}\text { rectangular } \\
\text { geometry }\end{array}$ & $\begin{array}{c}\text { hexagonal } \\
\text { geometry }\end{array}$ & $\begin{array}{c}\text { diamond } \\
\text { geometry }\end{array}$ \\
\hline$X_{o}(\%)$ & 1.50 & 1.00 & 1.13 & 0.96 \\
$X_{R}(\%)$ & 4.99 & 3.02 & 2.62 & 2.63 \\
$X(\%)$ & 6.42 & 3.99 & 3.72 & $\mathbf{3 . 5 6}$ \\
Reduction & & 37.85 & 42.05 & $\mathbf{4 4 . 5 5}$ \\
in losses $(\%)$ & 0 & & & \\
\hline
\end{tabular}

obtained with the diamond geometry is lower than that obtained by the other geometries. In Table 5.11, we can see that percentage of resistance losses of the hexagonal geometry and the diamond geometry are almost equal (around $2.62 \%$ ), but the percentage of shadowing losses of greater minimization was obtained by the diamond structure. For a solar cell of $2 \mathrm{x} 2 \mathrm{~mm}$ the diamond structure was the one that obtained the best performance in the minimization of the total losses, achieving $44.55 \%$ of reduction in losses.

In table 5.8 the results of the optimization process for solar cells of size $3 \times 3 \mathrm{~mm}$ were recorded, in the Figure 5.11 shows a best visualization of these results obtained from the optimization process for each of the geometries for a solar cell of height $h=2 \mu \mathrm{m}$. Each of the geometries obtained a considerable reduction in the total losses, the greatest loss minimization was obtained with the hexagonal geometry. For a $3 \mathrm{x} 3 \mathrm{~mm}$ solar cell, the hexagonal structure achieved a minimization of the total losses of $2.63 \%$, achieving a $47.71 \%$ reduction in losses.

With respect a solar cell of size $5 \times 5 \mathrm{~mm}$ the Table 5.16 recorded the results obtained from the optimization process of the three geometries for 


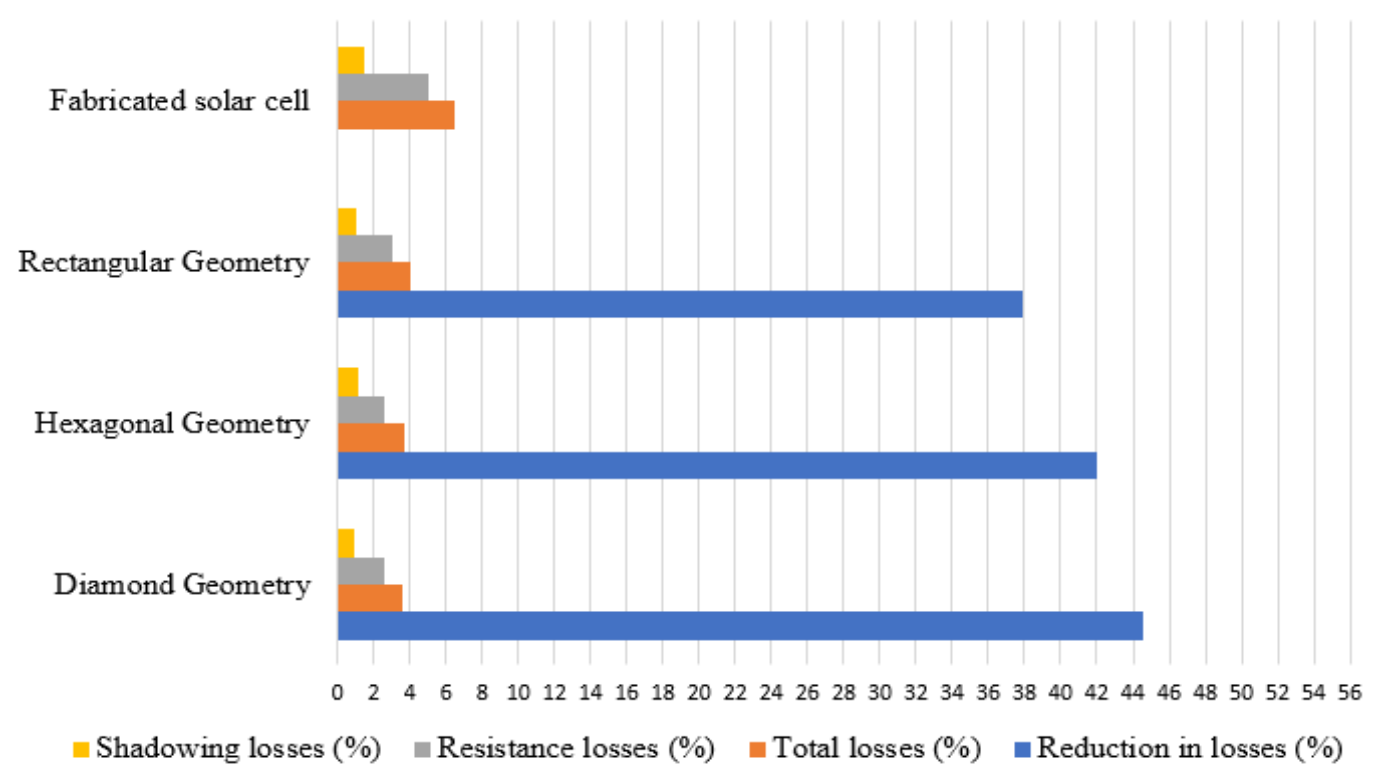

Figure 5.10: Losses of fabricated solar cell and each of the structures tested for a solar cell of size $2 \times 2 \mathrm{~mm}$.

a height $h=2 \mu \mathrm{m}$. Again it can be seen that each of the geometries obtained a considerable reduction in the total losses, but there is one that stands out, the total losses obtained with the rectangular geometry, is the greatest minimization of total losses that we have obtained during the entire optimization process. The Figure 5.12 shows a best visualization of these results. The minimization of the losses obtained by the other geometries is good but the rectangular geometry achieves a greater minimization of the losses due to shadowing and resistance. For a $5 \times 5 \mathrm{~mm}$ solar cell, the rectangular structure obtained the best performance in minimizing total losses, achieving a $54.42 \%$ reduction in losses.

Table 5.16: The best results obtained by GA for the geometries tested, size of the solar cell $5 \times 5 \mathrm{~mm}$.

\begin{tabular}{lcccc} 
& Fabricated & \multicolumn{3}{c}{ GA response, $h=2 \mu \mathrm{m}$} \\
\cline { 3 - 5 } & $\begin{array}{c}\text { solar cell } \\
h=0.215 \mu \mathrm{m}\end{array}$ & $\begin{array}{c}\text { rectangular } \\
\text { geometry }\end{array}$ & $\begin{array}{c}\text { hexagonal } \\
\text { geometry }\end{array}$ & $\begin{array}{c}\text { diamond } \\
\text { geometry }\end{array}$ \\
\hline$X_{o}(\%)$ & 3.00 & 1.10 & 1.53 & 1.43 \\
$X_{R}(\%)$ & 2.04 & 1.19 & 1.34 & 1.23 \\
$X(\%)$ & 4.98 & $\mathbf{2 . 2 7}$ & 2.84 & 2.64 \\
Reduction & & $\mathbf{5 4 . 4 2}$ & 42.97 & 46.99 \\
in losses $(\%)$ & 0 & & & \\
\hline
\end{tabular}

By Making a comparison of the best results obtained during the optimization process, with respect to the hexagonal structure, the GA did not find 


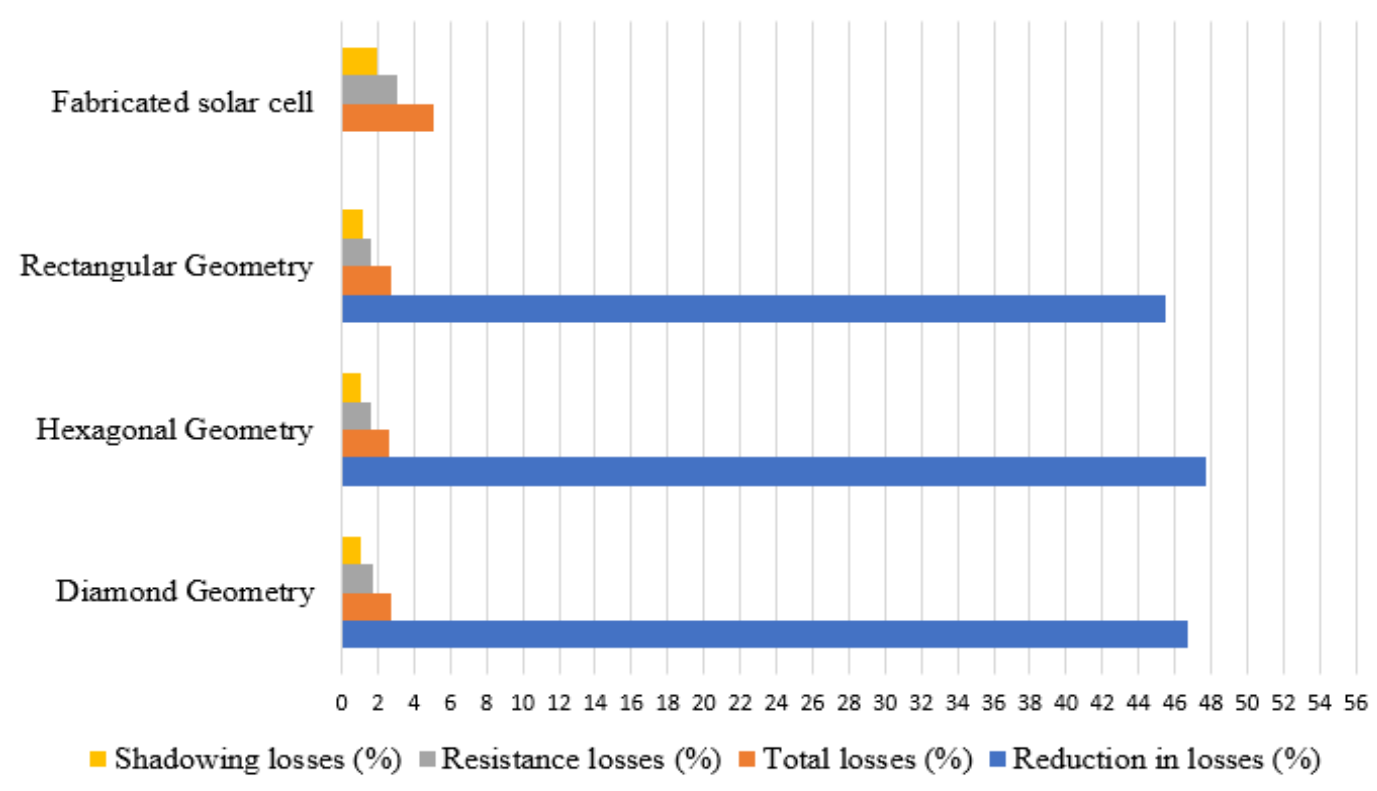

Figure 5.11: Losses of fabricated solar cell and each of the structures tested for a solar cell of size $3 \times 3 \mathrm{~mm}$.

a more optimal response after making the variation of the size of the solar cell, its best response was for the solar cell of size $3 \times 3 \mathrm{~mm}$ with a reduction in losses of $47.71 \%$. In diamond geometry, GA found a more optimal response when the optimization was performed for a solar cell of size $2 \times 2 \mathrm{~mm}$ with a reduction in losses of $44.55 \%$. The rectangular structure finds a better response surpassing those found by the other geometries when the cell size is $5 \times 5 \mathrm{~mm}$ with a loss reduction of $54.42 \%$.

For each size of solar cell the GA found optimal solutions, these solutions revealed that each geometry must have an ideal configuration in its structure, i.e., that the parameters for the manufacture of the grid of the solar cell should be optimized in conjunction with the length and width of the solar cell, thus allowing the structures to fit perfectly into the total area of the solar cell. 
Fabricated solar cell

Rectangular Geometry

Hexagonal Geometry

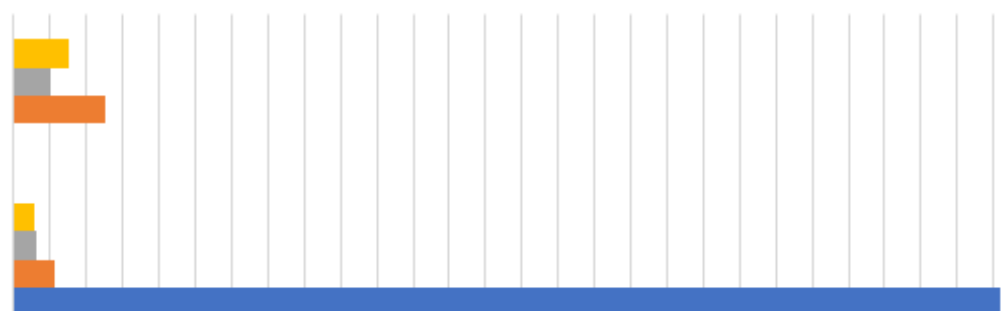

Diamond Geometry

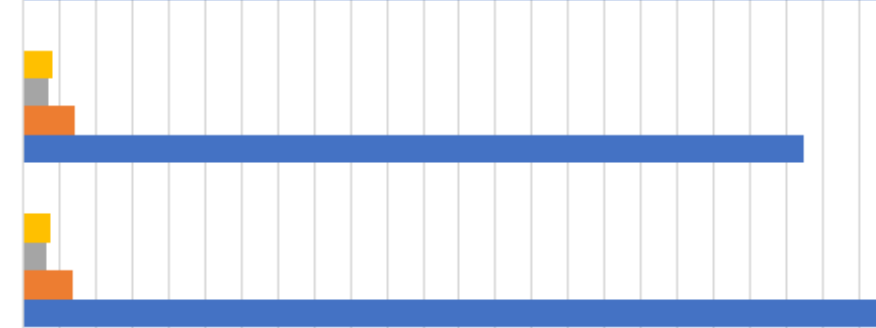

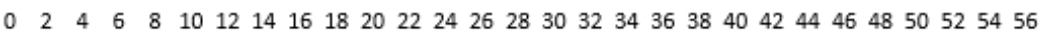

- Shadowing losses (\%) $\quad$ nesistance losses (\%) $\quad$ - Total losses (\%) $\quad$ - Reduction in losses (\%)

Figure 5.12: Losses of fabricated solar cell and each of the structures tested for a solar cell of size $5 \times 5 \mathrm{~mm}$. 


\section{6}

\section{Conclusions}

In this work, we show that genetic algorithms are useful in the process of optimization of the mesh of the collector's fingers for frontal electrical contact, leading to the minimization of the losses by electrical resistance and by shadowing in photovoltaic devices. In our analysis, we used the GA to find the best parameters for the construction of the collector's fingers in three different geometries, rectangular, hexagonal and diamond. A considerable reduction in total losses was observed for the three geometries optimized in relation to the rectangular structure used in the manufacture of a solar cell that we used for comparison. The fabricated structure was produced in our laboratory and was built based on analytical methods. To achieve these optimized results, several tests were performed that revealed that the configuration of the GA used only needed about 30 generations to converge to a satisfactory solution, the convergence is fast but sufficient to find optimal results.

The reduction of the losses related to the geometry and the construction parameters of the mesh of the fingers of the collector is of great importance to improve the efficiency of the solar cells. With respect to the variation of the height parameter, this showed to be of great importance in the optimization of the solar cell, contributing considerably to the minimization of resistance losses. With respect to the length of the collecting fingers, they are of great importance in the reduction of the losses due to shadowing. In general, the dimensions of the parameters in each of the structures play an important role in the minimization of total losses. The best structure found was for a $5 \times 5 \mathrm{~mm}$ solar cell with a rectangular geometry, with a loss reduction of $54.42 \%$ that leads to an approximate increase of $1.40 \%$ in efficiency.

It is important to carry out the physical design of each of the optimized geometries and to verify experimentally the validity of the theoretical results obtained, taking into account the limitations of the devices and the manufacturing methods in the solar cells. In addition, we must manufacture a solar cell taking into account the characteristics and structure of the reference solar cell, so that the data recorded in this work can be compared. To make this comparison, we must obtain the IV curves of each of the solar cells with the different geometries optimized. 
We find good results with the different geometries tested, there are still many geometries to be tested, there are possibilities to find a more efficient geometry. In the new geometries, it is important to make the respective changes in the equations, since the variation of the geometry alters the behavior of the losses in the solar cell. After the optimization process of the new geometry, we can make the respective comparisons with the results obtained in this work.

During the optimization process, the variation of the size of the solar cell revealed that each geometry must have an ideal configuration of structure that fits in the total area of the solar cell and that allows obtaining better results. For future tests, the length and width parameters of the solar cell can become GA input parameters, the independent variation of these parameters will increase the search range of a solution. It is possible that a better solution is found. In the new configuration of GA, we recommend that the range of variation of these parameters be configured in reals.

In this work we do not take into account the busbar, because the optimization is focused on the collector fingers, the dimensions of the solar cells to be optimized are small and generally used in photovoltaic solar concentration technology, where to perform the tests it is necessary to concentrate a large amount of solar radiation in a specific area of solar cells. For commercial type cells, the bus is important, since solar radiation affects the total area of the front contacts. If we want to perform an optimization of this type of cells, the area of the busbar must be included as the input parameter GA. For the optimization of this parameter, not only its dimensions must be taken into account, but also the location within the solar cell.

The GA configuration parameters together with the characteristics of the computer used for optimization define the delivery time of the optimal response. In our case, the computer used took approximately 8 hours for the delivery of the optimal response of the rectangular structure and approximately 12 hours for the hexagonal and diamond structure. The difference in times is due to the fact that the rectangular structure simulator evaluates the solutions faster because its code is shorter and simpler than for the other two structures. The delivery time of the results is considerable but the solutions are satisfactory for each of the structures tested, to decrease this delivery time of the optimal response we only need a computer with a higher processor and RAM, this will guarantee a good processing speed of data. If we want to add more input parameters in the optimization, using a computer with the same characteristics with which this work was developed, the time to obtain the optimized response will increase considerably, it is advisable to work with a computer with better characteristics. 


\section{Bibliography}

[1] SORENSEN, B. A history of renewable energy technology. Energy Policy, 19:8-12, 1991.

[2] JOHANSSON, T.; KELLY, H.; REDDY, A.; WILLIAMS, R. Renewable Energy: Sources For Fuels And Electricity. Island Press, California, USA, 2nd edition, 1991.

[3] EDENHOFER, O.;MADRUGA,R.; SOKONA, Y.; SEYBOTH, K. Renewable energy sources and climate change mitigation. Special report, Intergovernmental Panel on Climate Change, 2011.

[4] ANNING, V. Climate change and risk to fossil fuel industry: Sustainability train has left the station. phys.org, 2017. Acesso em: January 2018.

[5] EEA. Renewable energy in europe 2017 recent growth and knockon effects. EEA Report 3, European environment agency, 2017.

[6] IEA-IRENA. Perspectives for the energy transition: Investment needs for a low-carbon energy system. Special report, International Energy Agency, International Renewable Energy Agency, 2017.

[7] EUROPEAN COUNCIL. Conclusions on 2030 climate and energy policy framework. Brussels, European environment agency, 2014.

[8] REN21. Renewables 2017. global status report. Renewable Energy Policy Network for the 21st Century, 2017. Acesso em: January 2018.

[9] EUROPEAN ENVIRONMENT AGENCY. Indicative trajectories for the share of energy from renewable sources in gross final consumption of energy, from national renewable energy action plans. European commission, 2017. Acesso em: January 2018.

[10] FRANKFURT SCHOOL-UNEP. Global trends in renewable energy investment 2016. Special report, United nations environment program, Bloomberg new agency finance, 2016. 
[11] EEA. Shaping the future of energy in Europe. Special report, European environment agency, 2017.

[12] PONAKALA, V.; KUMAR, A. Design and simulation of small wind turbine blades in q-blade. International journal of Engineering development and research, 5:1095-1103, 2017.

[13] AHUJA, D.; TATSUTAN, M. Sustainable energy for developing countries. Surveys and Perspectives Integrating Environment and Society, 21, 2009.

[14] DENG, Y.; HAIGH, M.; POUWELS, W.; RAMAEKERS, L.; BRANDSMA, R.; SCHIMSCHAR, S.; GRÖZINGER, J.; JAGER, D. Quantifying a realistic, worldwide wind and solar electricity supply. Global Environmental Change, 31:239-252, 2015.

[15] WUSTENHAGEN, R.; WOLSINK, M.; RURER, M. J. Social acceptance of renewable energy innovation: An introduction to the concept. Energy Policy, 35:2683-2691, 2007.

[16] FTHENAKIS, V. M.; KIM H. C.; ANSELMA, E. Emissions from photovoltaic life cycles. Environmental Science Technology, 42:2168-2174, 2008.

[17] IEA. World energy investment 2017. Special report, INTERNATIONAL ENERGY AGENCY, 2017.

[18] MAYER, J. N.; PHILIPPS, S.; HUSSEIN, N. S.; SCHLEGL, T.; SENKPIEL, C. Current and future cost of photovoltaics. Special study $1,82 p$, Fraunhofer-Institute for Solar Energy Systems, ISE, 2015.

[19] PHILIPPS, S.; WARMUTH, W. Photovoltaics report. Special Report 1, 44p, Fraunhofer-Institute for Solar Energy Systems, ISE, 2017.

[20] HOROWITZ, A. W.; WOODhOUSE, M.; LEE, H.; SMESTAD, P. A bottom-up cost analysis of a high concentration pv module. In: 11TH INTERNATIONAL CONFERENCE ON CONCENTRATOR PHOTOVOLTAIC SYSTEMS, p. 1-59, Aix-le-Bains, F́rance, 2015.

[21] MOHANTY, P.; MUNEER, T.; GAGO, E. J.; KOTAK, Y. Solar radiation fundamentals and PV system components. Springer International Publishing, Switzerland, 1st edition, 2016.

[22] NREL. Best research-cell efficiencies. National Renewable Energy Laboratory, 2017. Acesso em: November 2017. 
[23] GONDEK, E. Optical optimization of organic solar cells. optical materials, 36:98-101, 2013.

[24] LIU, L.; LI, G. Thickness optimization of organic solar cells by optical transfer matrix. 11th IEEE International Conference on Nanotechnology, p. 332-336, 2011.

[25] KOVSARIAN, A.; JELODARIAN, P. Optimization and characterization of advanced solar cells based on thin-film a-si:h/sige heterostructure. 19th Iranian Conference on Electrical Engineering, p. 1-5, 2011.

[26] BULTMAN, J. H.; EIKELBOOM, D. W. K.; KINDERMAN, R. Fast and easy single step module assembly for back-contacted c-si solar cells with conductive adhesives. 3rd World Conference on Photovoltaic Energy Conversion, p. 979-982, 2003.

[27] MORVILLO, P.; BOBEICO, E.; FORMISANO, F.; ROCA, F. Influence of metal grid patterns on the performance of silicon solar cells at different illumination levels. Materials Science and Engineering, 159160:318-321, 2008.

[28] OBINATA, K.; TAKEDA, Y.; KATO, N.; MOTOHIRO, T. Over $10 \%$ gain of output power of medium-sized solar cells by an improvement of geometry of collector electrodes. International Journal of Photoenergy, 2013:11, 2013.

[29] HEEMSKERK, R. S. Topology optimisation of metallisation patterns in photovoltaic applications. Master thesis, Department of Precision and Microsystems Engineering, Delft University of Technology, Netherlands, 2013.

[30] SILVACO. Optimizing solar cell top metal contact design introduction. Simulation Standard, 25:12-15, 2015.

[31] HARRAG, A.; MESSALTI, S. Extraction of solar cell parameters using genetic algorithm. 4th International Conference on Electrical Engineering, p. 1-5, 2015.

[32] ATTARI, K.; AMHAIMAR, L.; YAAKOUBI, A.; ASSELMAN, A.; BASSOU, $M$. The design and optimization of gaas single solar cells using the genetic algorithm and silvaco atlas. International Journal of Photoenergy, 2017:1-7, 2017. 
[33] WANG, C.; YU, S.; CHEN W.; SUN, C. Highly efficient light-trapping structure design inspired by natural evolution. Scientific Reports, 3:1025, 2013.

[34] DJEFFAL, F.; BENDIB, T.; ARAR, D.; DIBI, Z. An optimized metal grid design to improve the solar cell performance under solar concentration using multiobjective computation. Materials Science and Engineering, 178:574-579, 2012.

[35] PIRES, A. Simulação e projeto de células solares com poços quânticos de GaAs/AlGaAs auxiliado por algoritmos genéticos. Dissertação de mestrado, Departamento de Engenharia elétrica, Pontifícia Universidade Católica do Rio de Janeiro, Rio de Janeiro, 2009.

[36] BAETAE, H.; JEON, T.R.; KIM, S. Optimization of silicon solar cell fabrication based on neural network and genetic programming modeling. Springer-Verlag, 14:161-169, 2010.

[37] BASORE, P. A. Optimum grid-line patterns for concentrator solar cells under nonuniform illumination. Solar cells, 14:249-260, 1985.

[38] HOLLAND, J. H. Adaptation in Natural and Artificial Systems:An Introductory Analysis with Applications to Biology, Control and Artificial Intelligence. University of Michigan Press, London, England, 1st edition, 1975.

[39] MAN, K.; TANG, K.; KWONG, S. Genetic Algorithms: Concepts and Desings. Springer Science Bussines Media, London, Great Britain, 3rd edition, 2001.

[40] GOLDBERG D. E. Genetic Algorithms in Search, Optimization and Machine Learning. Addison-Wesley Longman Publishing Co, MA, USA, 1st edition, 1989.

[41] HONSBERG, C.; BOWDEN, S. Standard solar spectra. Photovoltaic Education Network, 2017. Acesso em: November 2017.

[42] GOLDSMITH, N. T. Deep focus: a digital image processing technique to produce improved focal depth in light microscopy. Image Anal. Stereol, 19:163-167, 2000.

[43] VALDECASAS, A. G.; MARSHALL, D.; BECERRA, J. M.; TERRERO, J. J. On the extended depth of focus algorithms for bright field microscopy. Micron, 32 (6):559-569, 2001. 
[44] YOUNG, I. T. Shading correction: Compensation for illumination and sensor inhomogeneities. In: CURRENT PROTOCOLS IN CYTOMETRY, J.P. ROBINSON, ET AL., EDITORS., JOHN WILEY AND SONS, INC, p. 2.11.1-2.11.12, New York (NY, USA), 2000.

[45] SHOCKLEY, W.; QUEISSER. H.J. Detailed balance limit of efficiency of p-n junction solar cells. Journal of Applied Physics, 32:510-519, 1960.

[46] HONSBERG, C.; BOWDEN, S. Shunt resistance. Photovoltaic Education Network, 2017. Acesso em: November 2017.

[47] ZEITOUNY, J.; KATZ, E.; DOLLET, A.;VOSSIER, A. Band gap engineering of multi-junction solar cells: Effects of series resistances and solar concentration. Special reports 1, 9p, National Center for Scientific Research, CNRS-PROMES, 2017.

[48] GREEN, M. A. Solar cell efficiency tables (version 50). Progress in Photovoltaics: Research and Applications, 25:668-676, 2017.

[49] KERSCHAVER, E. V. ; BEAUCARNE, G. Back-contact solar cells: a review. Progress in Photovoltaics: Research and Applications, 14:107-123, 2006.

[50] SERREZE, H. B. Optimizing solar cell performance by simultaneous consideration of grid pattern design and interconnect configuration. In: 13TH IEEE PHOTOVOLTAIC SPECIALISTS CONFERENCE, p. 609-614, Washington DC, USA, 1978.

[51] WEN, L.; YUEQIANG, L.; JIANJUN, CH.; YANLING, CH.; XIAODONG, W.; FUHUA, Y. Optimization of grid design for solar cells. Journal of Semiconductors, 31:1, 2010.

[52] WYETH, N.C. Sheet resistance component of series resistance in a solar cell as a function of grid geometry. Solid State Electronics, 20:629-634, 1977.

[53] FRASER, A. S. Simulation of genetic systems by automatic digital computers. Australian journal of biological sciences, 10:484-491, 1957.

[54] MALHOTRA, R.; SINGH, N.; SINGH, Y. Genetic algorithms: Concepts, design for optimization of process controllers. Computer and Information Science, 4:No.2, 2011.

[55] MITCHELL, M. An introduction to genetic algorithms. MIT Press, London, England, 1st edition, 1998. 
[56] BÄCK, T. Evolutionary algorithms in theory and practice: evolution strategies, evolutionary programming, genetic algorithms. Oxford University Press, New York, 1st edition, 1996.

[57] FOGEL D.B.; FOGEL L.J. Genetic algorithms: Concepts, design for optimization of process controllers. European Conference on Artificial Evolution, 1063:21-33, 1996.

[58] ZEBULUM, R.; PACHECO, M.; VELLASCO, M. Evolutionary electronics: automatic design of electronic circuits and systems by genetic algorithms. CRC Press, FL, USA, 1st edition, 2001.

[59] BASTIDAS, J. Algoritmos genéticos aplicados à solução do problema inverso biomagnético. Dissertação de mestrado, Departamento de Engenharia elétrica, Pontifícia Universidade Católica do Rio de Janeiro, Rio de Janeiro, 2015.

[60] FLEMING, J.; PURSHOUSE, R. Evolutionary algorithms in control systems engineering: a survey. control engineering practice. Control Engineering Practice, 10:1223-1241, 2002.

[61] HOLLAND, J. H. Genetic algorithms. Scientific American, 267:66-72, 1992.

[62] MAARANEN, H.; MIETTINEN, K.; MÄKELÄ, M. Quasi-random initial population for genetic algorithms. Computers Mathematics with Applications, 47:1885-1895, 2004.

[63] DENG, Y.; LIU, Y.; ZHOU, D. An improved genetic algorithm with initial population strategy for symmetric tsp. Mathematical Problems in Engineering, 2015:1-6, 2015.

[64] BANDYOPADHYAY, S.; SAHA, S. Unsupervised Classification: similarity measures, classical and metaheuristic approaches, and applications. Springer-Verlag, Berlin, 1st edition, 2013.

[65] GOLDBERG, D.; RICHARDSON, J. Genetic algorithms with sharing for multimodal function optimization. Second International Conference on Genetic algorithms and their application, p. 41-49, 1987.

[66] ZHANG, G.; LU, J.; GAO, Y. Multi-Level Decision Making: Models, Methods and Applications. Springer-Verlag, Berlin, 1st edition, 2015. 
[67] MILLER, B.; SHAW, M. Genetic algorithms with dynamic niche sharing for multimodal function optimization. In IEEE International Conference on Evolutionary Computation, p. 786-791, 1995.

[68] CHEN, S.H. Genetic Algorithms and Genetic Programming in Computational Finance. Kluwer Academic Publishers, USA, 1st edition, 2002.

[69] DEB, K. Multi-objective genetic algorithms: problem difficulties and construction of test functions. Evolutionary Computation, 7:205230, 1999.

[70] MÜHLENBEIN, H.; SCHOMISCH, M.; BORN, J. The parallel genetic algorithm as function optimizer. Parallel Computing, 17:619-632, 1991.

[71] HARIK, G.; LOBO, F.; GOLDBERG, D. The compact genetic algorithm. IEEE Transactions on Evolutionary Computation, 3:287-297, 1999.

[72] GOH, K.; LIM, A.; RODRIGUES, B. Sexual selection for genetic algorithms. Artificial Intelligence Review, 19:123-152, 2003.

[73] GESTAL, M.; RIVERO, D.; RABUÑAL, J.; DORADO, J.; PAZOS, A. Introducción a los Algoritmos Genéticos y la Programación Genética. Servizo de Publicacións da UDC, Madrid, 1st edition, 2010.

[74] GÜNTER, R. Convergence analysis of canonical genetic algorithms. IEEE Transactions on Neural Networks, 5:96-101, 1994.

[75] VALENCIA, P. Optimización mediante algoritmos genéticos. Anales del Instituto de Ingenieros de Chile, p. 83-92, 1997.

[76] KAZARLIS, S.; BAKIRTZIS A.; PETIDRIS, V. A genetic algorithm solution to the unit commitment problem. IEEE Transactions on Power Systems, 11:No.1, 1996.

[77] POON, P.W. ; CARTER, J.N. Genetic algorithm crossover operators for ordering applications. Computers Operations Research, 22:135-147, 1995.

[78] HERRERA, F.; LOZANO, M.; SÁNCHEZ, A. A taxonomy for the crossover operator for real-coded genetic algorithms. International Journal of Intelligent Systems, 18:309-338, 2003. 
[79] DAVIS, L. Job shop scheduling with genetic algorithms. 1st International Conference on Genetic Algorithms, p. 136-140, 1985.

[80] LINDEN, R. Algoritmos Genéticos: Uma importante ferramenta da Inteligência Computacional. Brasport, Rio de Janeiro, 2nd edition, 2012.

[81] WEINER, E.; MICHA, D.; JAKOMIN, R.; PINTO, L.; PIRES, M.; SOUZA, $P$. Improving the figures of merit of intermediate band solar cells by controlling the capping procedure of the quantum dots. In: PROCEEDINGS OF THE IEEE 43RD PHOTOVOLTAIC SPECIALISTS CONFERENCE (PVSC), p. 2080-2083, Portland, OR, 2016. 